CAE Working Paper \#11-03

The Nature of Risk Preferences:

Evidence from Insurance Choices

by

Levon Barseghyan

Francesca Molinari

Ted O'Donoghue

and

Joshua Teitelbaum

July 2011 


\title{
The Nature of Risk Preferences: Evidence from Insurance Choices*
}

\author{
Levon Barseghyan ${ }^{\dagger}$ \\ Cornell University
}

Ted O'Donoghue

Cornell University

\author{
Francesca Molinari \\ Cornell University
}

\author{
Joshua C. Teitelbaum \\ Georgetown University
}

July 21,2010

\begin{abstract}
We use data on households' deductible choices in auto and home insurance to estimate a structural model of risky choice that incorporates "standard" risk aversion (concave utility over final wealth), loss aversion, and nonlinear probability weighting. Our estimates indicate that nonlinear probability weighting plays the most important role in explaining the data. More specifically, we find that standard risk aversion is small, loss aversion is nonexistent, and nonlinear probability weighting is large. When we estimate restricted models, we find that nonlinear probability weighting alone can better explain the data than standard risk aversion alone, loss aversion alone, and standard risk aversion and loss aversion combined. Our main findings are robust to a variety of modeling assumptions.

JEL classifications: D01, D03, D12, D81, G22
\end{abstract}

Keywords: deductible, loss aversion, probability weighting, risk aversion

${ }^{*}$ We are grateful to Darcy Steeg Morris for excellent research assistance. For helpful comments, we thank Matthew Rabin as well as seminar and conference participants at Berkeley, UCLA, the Second Annual Behavioral Economics Conference, the Summer 2010 Workshop on Behavioral/Institutional Research and Financial Regulation, FUR XIV, and the 85th Annual Conference of the Western Economic Association International. Barseghyan acknowledges financial support from the Institute for Social Sciences at Cornell University. Molinari acknowledges financial support from NSF grants SES-0617482 and SES-0922330.

${ }^{\dagger}$ Corresponding author: Levon Barseghyan, Department of Economics, Cornell University, 456 Uris Hall, Ithaca, NY 14853 (lb247@cornell.edu). 


\section{Introduction}

Households are averse to risk - for example, they require a premium to invest in equity and they purchase insurance at actuarially unfair rates. The standard expected utility model attributes risk aversion to a concave utility function defined over final wealth states (diminishing marginal utility for wealth). Research in behavioral economics, however, suggests that the standard account is inadequate. The leading alternative account, offered by prospect theory (Kahneman and Tversky 1979; Tversky and Kahneman 1992), posits that two additional features of risk preferences - loss aversion and nonlinear probability weighting - play important roles in explaining aversion to risk.

In this paper, we use data on households' deductible choices in auto and home insurance to estimate a structural model of risky choice that incorporates "standard" risk aversion (concave utility over final wealth), loss aversion, and nonlinear probability weighting. Our estimates indicate that nonlinear probability weighting plays the most important role in explaining the data. More specifically, we find that standard risk aversion is statistically significant but economically small, loss aversion is nonexistent, and nonlinear probability weighting is statistically and economically significant. When we estimate restricted models, we find that nonlinear probability weighting alone can better explain the data than standard risk aversion alone, loss aversion alone, and standard risk aversion and loss aversion combined.

Section 2 provides an overview of our data. The source of the data is a large U.S. property and casualty insurance company that offers multiple lines of insurance, including auto and home coverage. The full data set comprises yearly information on more than 400,000 households who held auto or home policies between 1998 and 2006. For each household, the data contain, inter alia, the household's deductible choices for three property damage coverages - auto collision, auto comprehensive, and home all perils. The data also include the household-coverage-specific menus of premium-deductible combinations that were available to each household when it made its deductible choices. In addition, the data contain each household's claims history for each coverage, as well as a rich set of demographic information. We utilize the data on claim realizations and demographics to assign to each household a household-coverage-specific predicted claim rate for each coverage.

Section 3 describes our theoretical framework. We first develop an underlying microeconomic model of deductible choice that incorporates standard risk aversion and loss aversion by adopting a variant of the model of reference-dependent preferences proposed by Köszegi and Rabin $(2006,2007)$. We then generalize the Köszegi-Rabin model to allow for rankdependent nonlinear probability weighting (Quiggin 1982), and we use the one-parameter probability weighting function proposed by Prelec (1998). In specifying our econometric 
model, we follow McFadden (1974, 1981) and assume random utility with additively separable choice noise. In addition, we permit each of the utility parameters to depend on observable household characteristics.

Section 4 presents the main estimation results. They suggest that nonlinear probability weighting plays the key role in explaining the households' deductible choices. Under our benchmark specification, the mean and median estimates of the coefficient of absolute risk aversion are $3.0 \cdot 10^{-5}$ and $1.0 \cdot 10^{-7}$, respectively; the mean and median estimates of the coefficient of loss aversion are both zero; and the mean and median estimates of the nonlinear probability weighting parameter (Prelec's $\alpha$ ) are both 0.7 (standard linear weighting involves $\alpha=1$ ). Qualitatively, our results imply a small role for standard risk aversion, little to no role for loss aversion, and a large role for nonlinear probability weighting. For example, we show that our benchmark estimates imply that standard risk aversion generates a negligible increase in willingness to pay for lower deductibles (relative to the actuarially fair premium), whereas nonlinear probability weighting generates a substantial increase.

Section 5 contains a sensitivity analysis. Most importantly, we consider other probability weighting functions, including the one-parameter function proposed by Tversky and Kahneman (1992). All in all, we find that our benchmark estimates are quite robust to alternative model specifications. We conclude the paper with a brief discussion in Section 6 .

Numerous previous studies structurally estimate risk preferences from observed choices, relying in most cases on nonmarket data (survey and experimental data) and in some cases on market data, including insurance data. The majority of the studies in the literature estimate models that incorporate only standard risk aversion. ${ }^{1}$ A minority, however, allow for loss aversion or nonlinear probability weighting, or both. ${ }^{2}$ Cicchetti and Dubin (1994), for instance, take an approach similar to ours, though they reach somewhat different conclusions. They use data on telephone customers' interior wire insurance choices to estimate a random utility model that allows for nonlinear probability weighting. While they find that the average customer has a relatively small degree of absolute risk aversion, ${ }^{3}$ they find only slight evidence that consumers weight line trouble probabilities nonlinearly. One limitation of their study, however, is that the interior telephone wire insurance market is characterized by extremely low, and tightly dispersed, stakes and claim probabilities. ${ }^{4}$ More recently, three

\footnotetext{
${ }^{1}$ Two that use data on deductible choices are Cohen and Einav (2007) and Sydnor (forthcoming). The latter discusses, but does not estimate, the Köszegi-Rabin model.

${ }^{2}$ In addition to the studies discussed below, see, e.g., Tversky and Kahneman (1992), Hey and Orme (1994), Jullien and Salanié (2000), Choi et al. (2007), Post et al. (2008), and Tanaka et al. (2010).

${ }^{3}$ We should note, however, that this result is a matter of dispute (Rabin and Thaler 2001; Grgeta 2003).

${ }^{4}$ The average consumer in their sample faces a price of $\$ 0.45$ per month to insure against a 0.5 percent chance of incurring a loss of $\$ 55$. The authors do not report the dispersion in stakes, but they do report that claim rates vary only from 0.3 percent to 0.7 percent.
} 
studies report findings comparable to ours, though each takes a different approach. Bruhin et al. (forthcoming) use experimental data on subjects' choices over binary money lotteries to estimate a mixture model of cumulative prospect theory. They find that approximately 20 percent of subjects can essentially be characterized as expected value maximizers, while approximately 80 percent of subject exhibit significant nonlinear probability weighting (and small to moderate money nonlinearity). Snowberg and Wolfers (forthcoming) use data on gamblers' bets on horse races to test the fit of two models - a model with standard risk aversion alone and a model with nonlinear probability weighting alone - and find that the latter model better fits their data. Kliger and Levy (2009) use data on call options on the S\&P 500 index to estimate a cumulative prospect theory model. Like us, they find that standard risk aversion is small and that nonlinear probability weighting is large, but, unlike us, they find evidence of loss aversion. A limitation of the latter two studies, however, is that they have only aggregate data, which necessitates that they take a representative agent approach and rely on equilibrium "ratio" conditions to identify the agent's utility function. Our paper complements these studies and contributes to the literature principally by utilizing disaggregated, market data in a setting of central interest to economists.

\section{Data Description}

\subsection{Overview and Core Sample}

We acquired the data from a large U.S. property and casualty insurance company. The company offers multiple lines of insurance, including auto, home, and umbrella policies. The full data set comprises yearly information on more than 400,000 households who held auto or home policies between 1998 and 2006. For each household, the data contain all the information in the company's records regarding the household's characteristics (other than identifying information) and its policies (e.g., the limits on liability coverages, the deductibles on property damage coverages, and the premiums associated with each coverage). The data also record the number of claims that each household filed with the company under each of its policies during the period of observation.

In this paper, we restrict attention to households who hold both auto and home policies and we focus on three choices: (i) the deductible for auto collision coverage; (ii) the deductible for auto comprehensive coverage; and (iii) the deductible for home all perils coverage. ${ }^{5}$ In

\footnotetext{
${ }^{5}$ Auto collision coverage pays for damage to the insured vehicle caused by a collision with another vehicle or object, without regard to fault. Auto comprehensive coverage pays for damage to the insured vehicle from all other causes (e.g., theft, fire, flood, windstorm, glass breakage, vandalism, hitting or being hit by an animal, or by falling or flying objects), without regard to fault. If the insured vehicle is stolen, auto
} 
addition, we consider only the initial deductible choices of each household. This is meant to increase confidence that we are working with active choices; one might be concerned that some households renew their policies without actively reassessing their deductible choices. Finally, we restrict attention to households who first purchased their auto and home policies from the company in the same year, in either 2005 or 2006. These restrictions are meant to avoid temporal issues, such as changes in household characteristics and in the economic environment. In the end, we are left with a core sample of 4170 households. Table 1 provides descriptive statistics for the variables we use later to estimate the households' utility parameters.

\section{TABLE 1}

\subsection{Deductibles and Premiums}

For each household in the core sample, we observe the household's deductible choices for auto collision, auto comprehensive, and home, as well as the premiums paid by the household for each type of coverage. In addition, the data contain the exact menus of premium-deductible combinations that were available to each household at the time it made its deductible choices. Table 2 summarizes the deductible choices of the households in the core sample. For each coverage, the most popular deductible choice is $\$ 500$. Table 3 summarizes the premium menus. For each coverage, it describes, for all households, the premium for coverage with a $\$ 500$ deductible, as well as the marginal cost of decreasing the deductible from $\$ 500$ to $\$ 250$ and the marginal benefit of increasing the deductible from $\$ 500$ to $\$ 1000$. (Tables A.1 through A.3 in the Appendix summarize the premium menus with households grouped by their deductible choice.) The average annual premium for coverage with a $\$ 500$ deductible is $\$ 180$ for auto collision, $\$ 115$ for auto comprehensive, and $\$ 679$ for home. The average annual cost of decreasing the deductible from $\$ 500$ to $\$ 250$ is $\$ 54$ for auto collision, $\$ 30$ for auto comprehensive, and $\$ 56$ for home. The average annual savings from increasing the deductible from $\$ 500$ to $\$ 1000$ is $\$ 41$ for auto collision, $\$ 23$ for auto comprehensive, and $\$ 74$ for home.

\section{TABLES $2 \& 3$}

As Table 3 suggests, there is considerable variation in premiums across households and coverages. To illuminate the sources of such variation, we provide a generalized description

comprehensive coverage also provides a certain amount per day for transportation expenses (e.g., rental car or public transportation). Home all perils coverage pays for damage to the insured home from all causes (e.g., fire, windstorm, hail, tornadoes, vandalism, or smoke damage), except those that are specifically excluded (e.g., flood, earthquake, or war). For simplicity, we often refer to home all perils simply as home. 
of the plan the company uses to rate a policy in each line of coverage. First, upon observing the household's coverage-relevant characteristics, $X$, the company determines a benchmark premium $\bar{p}$ (i.e., the premium associated with a benchmark deductible $\bar{d}$ ) according to a coverage-specific rating function, $\bar{p}=f(X)$. The rating function takes into account, inter alia, the household's risk tier and any applicable discounts. For each coverage, the company has roughly ten risk tiers. Assignment to a lower risk tier reduces the household's benchmark premium by a fixed percentage. These percentages are known in the industry as tier factors. Second, the company generates a household-specific menu $\left\{\left(p_{d}, d\right): d \in \mathcal{D}\right\}$, which associates a premium $p_{d}$ with each deductible $d$ in the coverage-specific set of deductible options $\mathcal{D}$, according to a coverage-specific multiplication rule, $p_{d}=(g(d) \cdot \bar{p})+c$, where $g(\cdot)>0$ (with $g(\bar{d})=1$ ) and $c>0$. The multiplicative factors $\{g(d): d \in \mathcal{D}\}$ are known in the industry as deductible factors, and $c$ is known as an expense fee. The deductible factors and the expense fees are coverage specific but household invariant. Moreover, the expense fees are fixed markups that do not depend on the deductibles. The company's rating plan, including its rating function and multiplication rule, are subject to state regulation. Among other things, the regulations require that the company base its rating plan on actuarial considerations (losses and expenses) and prohibit the company and its agents from charging rates that depart from the company's rating plan. ${ }^{6}$ It is safe to assume, therefore, that the variation in premiums is exogenous to the households' risk preferences, once we control for household characteristics.

\subsection{Claim Rates}

For purposes of our analysis, we need to estimate each household's (latent) claim rate for each coverage. To estimate the claim rates, we use the full data set: 1,348,020 household-year records for auto and 1,265,229 household-year records for home. For each household-year record, the data record the number of claims filed by the household in that year. We estimate a Poisson panel regression model with random effects for each of the three claim processes, regressing the number of claims on a battery of observables. For each household in the core sample, we use the regression estimates to generate a predicted annual claim rate for each coverage, and we treat the predicted claim rates as the household's true claim rates. ${ }^{7}$

More specifically, we assume that claims follow a Poisson distribution at the householdcoverage level. That is, we assume that household $i$ 's claims under coverage $j$ in year $t$ follow

\footnotetext{
${ }^{6}$ They also prohibit "excessive" rates and provide that insurers shall consider only "reasonable profits" in making rates. See, e.g., N.Y. Ins. Law $\S \S 2303,2304$ \& 2314 (Consol. 2010), N.Y. Comp. Codes R. \& Regis. tit. 11, § 160.2 (2010), and Dunham (2009, §§ $26.03 \& 43.10)$.

${ }^{7}$ We note that our approach is closely related to the approach taken by Barseghyan et al. (forthcoming).
} 
a Poisson distribution with arrival rate $\mu_{i j t}$. Under this assumption, the household's claim arrivals are independent within each coverage and across coverages. In addition, we assume that deductible choices do not influence claim rates, i.e., households do not suffer from moral hazard. ${ }^{8}$ We treat the claim rates as latent random variables and assume that

$$
\ln \mu_{i j t}=\beta_{j} X_{i j t}+\epsilon_{i j}
$$

where $X_{i j t}$ is a vector of observables, ${ }^{9} \epsilon_{i j}$ is an unobserved iid error term, and $\exp \left(\epsilon_{i j}\right)$ follows a gamma distribution with unit mean and variance $\phi_{j}$. On the basis of the foregoing assumptions, we perform standard Poisson panel regressions with random effects to obtain maximum likelihood estimates of $\beta_{j}$ and $\phi_{j}$ for each coverage $j$. The estimates are reported in Tables A.4 and A.5 in the Appendix. For each household $i$, we then use these estimates to generate a predicted claim rate $\widehat{\mu}_{i j}$ for each coverage $j$, conditional on the household's (ex ante) characteristics $X_{i j}$ and (ex post) claims experience.

Table 4 summarizes the predicted claim rates for the core sample. The mean predicted claim rates for auto collision, auto comprehensive, and home are 0.072, 0.021, and 0.089, respectively, and there is substantial variation across households and coverages. Table 4 also reports pairwise correlations among the predicted claim rates and between the predicted claim rates and the premiums for coverage with a $\$ 500$ deductible. Each of the pairwise correlations is positive, as expected, though none are large.

\section{TABLE 4}

\section{Theoretical Framework}

In this section, we describe our theoretical framework. First, we develop a microeconomic model of deductible choice. We then specify our econometric model, outline our estimation procedure, and discuss identification.

\subsection{A Microeconomic Model of Deductible Choice}

We assume that a household treats its deductible choices as independent decisions. This assumption is motivated, in part, by computational considerations, ${ }^{10}$ but also by the literature on "narrow bracketing" (e.g., Read et al. 1999), which suggests that when people make

\footnotetext{
${ }^{8}$ See infra footnotes 12 and 13 .

${ }^{9}$ In addition to the variables in Table $1, X_{i j t}$ includes numerous other variables (see Tables A.4 and A.5 in the Appendix).

${ }^{10}$ If instead we were to assume that a household treats its deductible choices as a joint decision, then the household would face 180 options and the utility function would have over 350 terms.
} 
multiple choices, they frequently do not assess the consequences of all choices at once, but rather tend to make each choice in isolation. Thus, we develop a model for how a household chooses the deductible for a single type of insurance coverage. The coverage provides full insurance against covered losses in excess of the deductible. To simplify notation, we suppress the subscripts for household and coverage (though we remind the reader that premiums and claim rates are household and coverage specific).

The household faces a menu of premium-deductible pairs $\left\{\left(p_{d}, d\right): d \in \mathcal{D}\right\}$, where $p_{d}$ is the premium associated with deductible $d$ and $\mathcal{D}$ is the coverage-specific set of deductible options. In principle, over the course of the policy period, the household may experience zero claims, one claim, two claims, three claims, and so forth. We assume that the number of claims follow a Poisson distribution with arrival rate $\mu$, and, for simplicity, we assume that each household experiences at most two claims. ${ }^{11}$ Hence, the probability of having zero claims is $\mu_{0} \equiv \exp (-\mu)$, the probability of having one claim is $\mu_{1} \equiv \mu \exp (-\mu)$, and the probability of having two or more claims is $\mu_{2} \equiv 1-\mu_{0}-\mu_{1}$. In addition, we assume that the household's choice of deductible does not influence $\mu$ (i.e., there is no moral hazard), ${ }^{12}$ and that every claim exceeds the highest available deductible. ${ }^{13}$ Finally, we assume that the household knows $\mu$ (or, alternatively, that its subjective belief about its claim rate corresponds to $\mu$ ). Under the foregoing assumptions, the choice of deductible involves a choice among lotteries of the form

$$
L_{d} \equiv\left(-p_{d}, \mu_{0} ;-p_{d}-d, \mu_{1} ;-p_{d}-2 d, \mu_{2}\right),
$$

to which we refer as deductible lotteries.

We allow for the possibility that the household's preferences over deductible lotteries are influenced by standard risk aversion, loss aversion, and nonlinear probability weighting. We incorporate standard risk aversion and loss aversion by adopting the model of referencedependent preferences proposed by Köszegi and Rabin (2006, 2007). In the Köszegi-Rabin (KR) model, the utility from choosing lottery $Y \equiv\left(y_{n}, q_{n}\right)_{n=1}^{N}$ given a reference lottery $\tilde{Y} \equiv\left(\tilde{y}_{m}, \tilde{q}_{m}\right)_{m=1}^{M}$ is

$$
U(Y \mid \tilde{Y}) \equiv \sum_{n=1}^{N} \sum_{m=1}^{M} q_{n} \tilde{q}_{m}\left[u\left(y_{n}\right)+v\left(y_{n} \mid \tilde{y}_{m}\right)\right]
$$

\footnotetext{
${ }^{11}$ Because claim rates are small (typically less than 0.1 , and almost always less than 0.3 ), the likelihood of more than two claims is very small. Even for a claim rate of 0.3 , for instance, the probability of more than two claims is 0.0036 .

${ }^{12}$ More specifically, we assume there is neither ex ante moral hazard (deductible choice does not influence the frequency of claimable events) nor ex post moral hazard (deductible choice does not influence the decision to file a claim).

${ }^{13}$ For arguments and evidence in support of the latter two assumptions, see Cohen and Einav (2007), Sydnor (forthcoming), and Barseghyan et al. (forthcoming).
} 
The function $u$ represents standard "intrinsic" utility defined over final wealth states, and standard risk aversion is captured by the concavity of $u$. The function $v$ represents the "gainloss" utility that results from experiencing gains or losses relative to the reference point. For $v$, we follow KR and use the functional form

$$
v(y \mid \tilde{y})=\left\{\begin{array}{cl}
\eta[u(y)-u(\tilde{y})] & \text { if } u(y)>u(\tilde{y}) \\
\eta \lambda[u(y)-u(\tilde{y})] & \text { if } u(y) \leq u(\tilde{y})
\end{array} .\right.
$$

In this formulation, the magnitude of gain-loss utility is determined by the intrinsic utility gain or loss relative to consuming the reference point. Moreover, gain-loss utility takes a two-part linear form, where $\eta \geq 0$ captures the importance of gain-loss utility relative to intrinsic utility and $\lambda \geq 1$ captures loss aversion. The model reduces to expected utility when $\eta=0$ or $\lambda=1$. But for $\eta>0$ and $\lambda>1$, the household's behavior is influenced by risk aversion (via $u$ ) and loss aversion (via $v$ ).

KR propose that the reference lottery equals recent expectations about outcomes - i.e., if a household expects to face lottery $\tilde{Y}$, then its reference lottery becomes $\tilde{Y}$. However, because situations vary in terms of when a household deliberates about its choices and when it commits to its choices, KR offer a number of solution concepts for the determination of the reference lottery. We assume that the reference lottery is determined according to what KR call a "choice-acclimating personal equilibrium" (CPE). Formally:

Definition (CPE). Given a choice set $\mathcal{Y}$, a lottery $Y \in \mathcal{Y}$ is a choice-acclimating personal equilibrium if for all $Y^{\prime} \in \mathcal{Y}, U(Y \mid Y) \geq U\left(Y^{\prime} \mid Y^{\prime}\right)$.

In a CPE, a household's reference lottery corresponds to its choice. KR argue that CPE is appropriate in situations where the household commits to a choice well in advance of the resolution of uncertainty, and thus it knows that by the time the uncertainty is resolved and it experiences utility, it will have become accustomed to its choice and hence expect the lottery induced by its choice. ${ }^{14}$ In particular, KR suggest that CPE is the appropriate solution concept for insurance applications.

Under the KR model using CPE, the utility to the household from choosing deductible

\footnotetext{
${ }^{14}$ The assumption that the household commits to its choice is important. Suppose instead that the household has the opportunity to revise its choice just before the uncertainty is resolved. Then even after "choosing" $Y$ and coming to expect it, if $U\left(Y^{\prime} \mid Y\right)>U(Y \mid Y)$ the household would want to revise its choice just before the uncertainty is resolved. KR propose alternative solution concepts that are more appropriate in such situations, where a household thinks about the problem in advance but does not commit to a choice until just before the uncertainty is resolved.
} 
lottery $L_{d}=\left(-p_{d}, \mu_{0} ;-p_{d}-d, \mu_{1} ;-p_{d}-2 d, \mu_{2}\right)$ is

$$
\begin{aligned}
U\left(L_{d} \mid L_{d}\right)= & \mu_{0} u\left(w-p_{d}\right)+\mu_{1} u\left(w-p_{d}-d\right)+\mu_{2} u\left(w-p_{d}-2 d\right) \\
& -\Lambda \mu_{0} \mu_{1}\left[u\left(w-p_{d}\right)-u\left(w-p_{d}-d\right)\right] \\
& -\Lambda \mu_{0} \mu_{2}\left[u\left(w-p_{d}\right)-u\left(w-p_{d}-2 d\right)\right] \\
& -\Lambda \mu_{1} \mu_{2}\left[u\left(w-p_{d}-d\right)-u\left(w-p_{d}-2 d\right)\right]
\end{aligned}
$$

where $\Lambda=\eta(\lambda-1)$ and $w$ is the household's initial wealth. From equation (1), it is clear that we can not separately identify the parameters $\eta$ and $\lambda$. Instead, we estimate the product $\eta(\lambda-1) \equiv \Lambda^{15}$ We refer to $\Lambda$ as the coefficient of "net" loss aversion.

Next, we incorporate nonlinear probability weighting. In their original prospect theory paper, Kahneman and Tversky (1979) suggest that certain choice phenomena are best captured by nonlinear probability weighting, whereby individual probabilities are transformed into decision weights. Their original approach, however, encounters problems - most notably, violations of stochastic dominance - which Quiggin (1982) solves by proposing a rankdependent approach. Instead of transforming individual probabilities into decision weights, the decumulative distribution of each lottery is transformed into a vector of decision weights for that lottery, where the decision weights sum to one. Over the years, several forms of nonlinear probability weighting have been proposed (e.g., Tversky and Kahneman 1992; Lattimore et al. 1992; Prelec 1998). We adopt the rank-dependent approach of Quiggin (1982) and use the one-parameter probability weighting function proposed by Prelec (1998). ${ }^{16}$

Formally, for deductible lottery $L_{d} \equiv\left(-p_{d}, \mu_{0} ;-p_{d}-d, \mu_{1} ;-p_{d}-2 d, \mu_{2}\right)$, we assume the decision weights are

$$
\begin{aligned}
\omega_{0} & \equiv \pi\left(\mu_{0}\right) \\
\omega_{1} & \equiv \pi\left(\mu_{1}+\mu_{0}\right)-\pi\left(\mu_{0}\right) \\
\omega_{2} & \equiv 1-\pi\left(\mu_{1}+\mu_{0}\right),
\end{aligned}
$$

where the probability weighting function $\pi$ is given by

$$
\pi(\mu)=\exp \left(-(-\ln \mu)^{\alpha}\right)
$$

\footnotetext{
${ }^{15}$ The inability to separately identify $\eta$ and $\lambda$ applies to any application of CPE, and not just deductible lotteries, because for any lottery $Y, \eta$ and $\lambda$ appear in $U(Y \mid Y)$ only as the product $\eta(\lambda-1)$. For other solution concepts, $\eta$ and $\lambda$ become separately identified.

${ }^{16}$ In Section 5.1, we confirm that our results are robust to a transformation of the cumulative distribution. We also confirm the robustness of our results to several other probability weighting functions.
} 
with $0<\alpha \leq 1$. Note that (2) nests standard linearity in the probabilities for $\alpha=1 .^{17}$

Generalizing the KR model to allow for nonlinear probability weighting requires that we specify the decision weights for both the chosen lottery and the reference lottery. KR offer no guidance on this modeling choice, as they abstract from nonlinear decision weights. To our minds, it seems natural to assume that households treat the chosen lottery and the reference lottery symmetrically. Accordingly, we assume that the decision weights are the same for the chosen lottery and the reference lottery.

Given the foregoing assumptions, the household chooses a deductible lottery to maximize equation (1), except that the claim probabilities $\mu_{0}, \mu_{1}$, and $\mu_{2}$ are replaced by the decision weights $\omega_{0}, \omega_{1}$, and $\omega_{2}$.

\subsection{Econometric Model}

To specify our econometric model, we first must account for observationally equivalent households choosing different deductibles. We follow McFadden $(1974,1981)$ and assume random utility with additively separable choice noise. Specifically, we assume that the utility from deductible $d \in \mathcal{D}$ is given by

$$
V(d) \equiv \tilde{U}\left(L_{d} \mid L_{d}\right)+\varepsilon_{d}
$$

where $\tilde{U}\left(L_{d} \mid L_{d}\right) \equiv U\left(L_{d} \mid L_{d}\right) / u^{\prime}(w)$ and $\varepsilon_{d}$ is an iid random variable. In $\tilde{U}$, we divide $U$ by $u^{\prime}(w)$ to normalize the scale of utility. The term $\varepsilon_{d}$ represents error in evaluating utility (Hey and Orme 1994). We assume that $\varepsilon_{d}$ follows a type 1 extreme value distribution with scale parameter $\sigma{ }^{18}$ Hence, a household chooses deductible $d$ when $V(d)>V\left(d^{\prime}\right)$ for all $d^{\prime} \neq d$, or equivalently when

$$
\varepsilon_{d^{\prime}}-\varepsilon_{d}<\tilde{U}\left(L_{d} \mid L_{d}\right)-\tilde{U}\left(L_{d^{\prime}} \mid L_{d^{\prime}}\right) \text { for all } d^{\prime} \neq d
$$

The probability that the household chooses deductible $d$ is

$$
\begin{aligned}
\operatorname{Pr}(d) & =\operatorname{Pr}\left(\varepsilon_{d^{\prime}}-\varepsilon_{d}<\tilde{U}\left(L_{d} \mid L_{d}\right)-\tilde{U}\left(L_{d^{\prime}} \mid L_{d^{\prime}}\right) \text { for all } d^{\prime} \neq d\right) \\
& =\frac{\exp \left(\tilde{U}\left(L_{d} \mid L_{d}\right) / \sigma\right)}{\sum_{d^{\prime} \in \mathcal{D}} \exp \left(\tilde{U}\left(L_{d^{\prime}} \mid L_{d^{\prime}}\right) / \sigma\right)} .
\end{aligned}
$$

\footnotetext{
${ }^{17}$ Figure 1 depicts (2) for $\alpha=0.7$ (our benchmark estimate).

${ }^{18}$ The scale parameter $\sigma$ is a monotone transformation of the variance of $\varepsilon_{d}$, and thus a larger $\sigma$ means larger variance.
} 
In the estimation, we construct the likelihood function from these choice probabilities (see Section 3.3).

Next, we must specify intrinsic utility $u$. In our main analysis, we follow Cohen and Einav (2007) and Barseghyan et al. (forthcoming) and consider a second-order Taylor expansion of the utility function $u(w-\Delta)$ around $w$. This yields

$$
\frac{u(w-\Delta)}{u^{\prime}(w)}-\frac{u(w)}{u^{\prime}(w)}=-\Delta-\frac{r}{2} \Delta^{2},
$$

where $r \equiv-u^{\prime \prime}(w) / u^{\prime}(w)$ is the coefficient of absolute risk aversion. Applied to equation (1) with nonlinear probability weighting, this yields

$$
\begin{aligned}
\tilde{U}\left(L_{d} \mid L_{d}\right)-\frac{u(w)}{u^{\prime}(w)}= & -\left[p_{d}+\omega_{1} d+\omega_{2} 2 d\right] \\
& -\frac{r}{2}\left[\omega_{0}\left(-p_{d}\right)^{2}+\omega_{1}\left(-p_{d}-d\right)^{2}+\omega_{2}\left(-p_{d}-2 d\right)^{2}\right] \\
& -\Lambda\left[\omega_{0} \omega_{1} d+\omega_{0} \omega_{2} 2 d+\omega_{1} \omega_{2} d\right] \\
& +\Lambda \frac{r}{2}\left\{\begin{array}{l}
\omega_{0} \omega_{1}\left[\left(p_{d}\right)^{2}-\left(p_{d}+d\right)^{2}\right] \\
+\omega_{0} \omega_{2}\left[\left(p_{d}\right)^{2}-\left(p_{d}+2 d\right)^{2}\right] \\
+\omega_{1} \omega_{2}\left[\left(p_{d}+d\right)^{2}-\left(p_{d}+2 d\right)^{2}\right]
\end{array}\right\} .
\end{aligned}
$$

Note that because the term $u(w) / u^{\prime}(w)$ appears for all $n$, it does not affect the choice probabilities, and thus the choice probabilities are independent of $w$.

The first term on the right-hand side of equation (5) reflects an expected value with respect to the decision weights. The second term is due to standard risk aversion - it is the sum of second-order differences in actual payoffs in the three states of the world, weighted by their respective decision weights and scaled by the household's standard risk aversion parameter. The third term arises from loss aversion-because payment of the premium occurs in all states of the world, it is not perceived as a loss under CPE. The last term is the "interaction" term between loss aversion and standard risk aversion-because premium payments do not directly affect the household's utility through loss aversion, it is only the second-order differences in payoffs, scaled by the standard risk aversion and net loss aversion parameters, that are relevant for the household's utility.

Note that, with this specification, we estimate a local approximation of the household's coefficient of absolute risk aversion. This approach is instrumental to our purposes, because even with the scale normalization, $u(w-\Delta) / u^{\prime}(w)$ can depend on $w$, which we do not observe (though we note that, in Section 4.2, we endeavor to account for wealth by using 
home value as a proxy). ${ }^{19}$ Moreover, this specification provides insight into important classes of utility functions. In particular, it is an exact approximation for quadratic utilities, which are commonly used in finance, and it is an appropriate approximation for plausible CRRA utilities -if $u(w)=w^{1-\rho} /(1-\rho), \rho>0$, then for $\Delta$ on the order of $\$ 1000, \rho$ in the low single digits, and wealth on the order of $\$ 100,000$, each term in the full Taylor expansion of $u(w-\Delta)$ around $w$ is roughly 1 percent of the magnitude of the prior term.

Finally, in our main analysis we assume that the household's true claim rate $\mu$ corresponds to its predicted claim rate $\widehat{\mu}$ (see Section 2.3). Thus, the decision weights are specified as

$$
\begin{aligned}
\omega_{0} & \equiv \pi\left(\widehat{\mu}_{0}\right) \\
\omega_{1} & \equiv \pi\left(\widehat{\mu}_{1}+\widehat{\mu}_{0}\right)-\pi\left(\widehat{\mu}_{0}\right) \\
\omega_{2} & \equiv 1-\pi\left(\widehat{\mu}_{1}+\widehat{\mu}_{0}\right),
\end{aligned}
$$

where $\widehat{\mu}_{0} \equiv \exp (-\widehat{\mu}), \widehat{\mu}_{1} \equiv \widehat{\mu} \exp (-\widehat{\mu})$, and $\pi$ is defined by equation (2). We note that while this approach captures heterogeneity in claim rates based on observables, it does not account for potential unobserved heterogeneity, which could lead to $\mu \neq \widehat{\mu}$. In other words, even if the household knows (or believes) $\mu$ to be its true claim rate (as we assume), the predicted claim rate $\widehat{\mu}$ may not correspond to $\mu$ due to unobserved heterogeneity. Indeed, Cohen and Einav (2007) and Barseghyan et al. (forthcoming) find evidence of unobserved heterogeneity in claim rates, though in both studies the degree of unobserved heterogeneity is relatively small. We endeavor to account for unobserved heterogeneity in an extension of our main analysis (see Section 4.3).

\subsection{Estimation Procedure}

We observe data $\left\{D_{i j}, \Gamma_{i j}\right\}$, where $D_{i j}$ is household $i$ 's deductible choice for coverage $j$ and $\Gamma_{i j} \equiv\left(Z_{i}, \widehat{\mu}_{i j}, P_{i j}\right)$. In $\Gamma_{i j}, Z_{i}$ is a vector of household characteristics, $\widehat{\mu}_{i j}$ is household $i$ 's predicted claim rate for coverage $j$ (as described in Section 2.3), and $P_{i j}$ denotes household $i$ 's menu of premiums for coverage $j$. In our benchmark specification, $Z_{i}$ comprises a constant and the variables in Table 1, except for home value (see Section 4.1). In all specifications, $Z_{i}$ is a strict subset of the vector of observables $X_{i j}$ that we use to generate $\widehat{\mu}_{i j}$.

There are four model parameters to be estimated:

\footnotetext{
${ }^{19}$ Alternately, we could assume CARA utility, for which $u(w-\Delta) / u^{\prime}(w)$ is independent of $w$. While we view CARA utility as too restrictive, we note that our main conclusions also hold for the CARA specification (see Section 5.2).
} 
$r$ - the coefficient of absolute risk aversion ( $r=0$ means no risk aversion);

$\Lambda$ - the coefficient of net loss aversion ( $\Lambda=0$ means no loss aversion);

$\alpha$ - the degree of nonlinear probability weighting ( $\alpha=1$ means linearity); and

$\sigma$ - the scale of choice noise ( $\sigma=0$ means no choice noise).

In our main analysis, we assume that $\sigma$ does not vary across households or coverages. However, we allow the preference parameters to depend on household characteristics $Z_{i}$ as follows:

$$
\begin{aligned}
\ln r_{i} & =\beta_{r} Z_{i} \\
\ln \Lambda_{i} & =\beta_{\Lambda} Z_{i} \\
\ln \alpha_{i} & =\beta_{\alpha} Z_{i}
\end{aligned}
$$

We estimate the model via maximum likelihood using combined data for all three coverages. For each household $i$, the conditional loglikelihood function is

$$
\ell_{i}(\theta) \equiv \sum_{j} \sum_{d \in \mathcal{D}_{j}} 1\left(D_{i j}=d\right) \ln \left[\operatorname{Pr}\left(D_{i j}=d \mid \Gamma_{i j}, \theta\right)\right]
$$

where $\theta=\left(\beta_{r}, \beta_{\Lambda}, \beta_{\alpha}, \sigma\right)$, the indicator function selects the deductible chosen by household $i$ for coverage $j$, and $\operatorname{Pr}\left(D_{i j}=d \mid \Gamma_{i j}, \theta\right)$ denotes the choice probability in equation (4). We

estimate $\theta$ by maximizing $\sum_{i} \ell_{i}(\theta)$. We then use $\widehat{\theta}$ to assign fitted values of $r_{i}, \Lambda_{i}$, and $\alpha_{i}$ to each household $i$.

As noted above, we assume that households treat their deductible choices as independent decisions, and we also assume no coverage-specific effects. In Section 5.5, we revisit these assumptions by both estimating the model separately for each coverage and estimating the model with coverage-specific choice noise.

\subsection{Identification}

In this section, we demonstrate that if there is sufficient variation in premiums and claim rates for a fixed array of observables $Z$, then the preference parameters $r, \Lambda$, and $\alpha$ are identified. We then argue that our data indeed contain significant variation in premiums and claim rates even for a fixed $Z$.

The random utility model in equation (3) comprises the sum of a utility function $\tilde{U}\left(L_{d} \mid L_{d}\right)$ and an error term $\varepsilon_{d}$. Using the results of Matzkin (1991), normalizations that fix scale and location, plus regularity conditions that are satisfied in our model, allow us to identify nonparametrically the utility function $\tilde{U}\left(L_{d} \mid L_{d}\right)$ within the class of monotone and concave utility functions. A fortiori, this guarantees parametric identification of $\tilde{U}\left(L_{d} \mid L_{d}\right)$. 
This in turn allows us to separately identify standard risk aversion $(r)$, net loss aversion $(\Lambda)$, and nonlinear probability weighting $(\alpha)$. To see the source of identification intuitively, consider the following example. Suppose we observe that a household with a 10 percent claim rate in auto collision chooses to pay $\$ 60$ to decrease its deductible from $\$ 1000$ to $\$ 500$. The household's choice, which implies a lower bound on its maximum willingness to pay $(W T P)$ to decrease its expected loss from $\$ 100$ to $\$ 50$, is consistent with numerous combinations of different degrees of standard risk aversion, loss aversion, and nonlinear probability weighting. ${ }^{20}$ However, different combinations yield different implications for other choices. For instance, different combinations would imply different lower bounds on the household's WTP to further decrease its auto collision deductible. They also would imply different lower bounds on the household's $W T P$ to decrease its deductible in other coverages, for which the household has a different claim rate. In short, different combinations of standard risk aversion, loss aversion, and nonlinear probability weighting have different implications for the observed distribution of deductibles, premiums, and claim rates.

Formally, then, we must demonstrate that the utility differences between deductible choices react in different ways to changes in the three preference parameters. Consider two deductible options, $a$ and $b$, and suppose that the probability of experiencing two claims is negligible, so that $\omega_{0}=\pi\left(\mu_{0}\right)=\pi(\exp (-\mu))=\exp \left(-\mu^{\alpha}\right)$ and $\omega_{1}=1-\omega_{0} \cdot{ }^{21}$ Applying equation (5) to this case, the difference in the household's utility from choosing deductible lotteries $L_{a}$ and $L_{b}$ is given by

$$
\begin{aligned}
\tilde{U}\left(L_{a} \mid L_{a}\right)-\tilde{U}\left(L_{b} \mid L_{b}\right)= & \left(p_{b}-p_{a}\right)+\omega_{1}(b-a) \\
& +\Lambda \omega_{0} \omega_{1}(b-a) \\
& +\frac{r}{2}\left\{\omega_{0}\left(p_{b}^{2}-p_{a}^{2}\right)+\omega_{1}\left[\left(p_{b}+b\right)^{2}-\left(p_{a}+a\right)^{2}\right]\right\} \\
& +\Lambda \frac{r}{2} \omega_{0} \omega_{1}\left\{\left[\left(p_{b}+b\right)^{2}-\left(p_{a}+a\right)^{2}\right]-\left(p_{b}^{2}-p_{a}^{2}\right)\right\} .
\end{aligned}
$$

We can rewrite equation (6) as

$$
\begin{aligned}
\tilde{U}\left(L_{a} \mid L_{a}\right)-\tilde{U}\left(L_{b} \mid L_{b}\right)= & \left(p_{b}-p_{a}\right)+\Omega(\mu)(b-a)+\frac{r}{2}\left(p_{b}^{2}-p_{a}^{2}\right) \\
& +\Omega(\mu) \frac{r}{2}\left\{\left[\left(p_{b}+b\right)^{2}-\left(p_{a}+a\right)^{2}\right]-\left(p_{b}^{2}-p_{a}^{2}\right)\right\},
\end{aligned}
$$

\footnotetext{
${ }^{20}$ For the avoidance of doubt, throughout the paper we use $W T P$ to denote maximum willingness to pay.

${ }^{21}$ These assumptions are without loss of generality. If the model is identified for the case where households have two deductible options and can experience at most one claim, then it also is identified where households have more than two deductible options and can experience more than one claim.
} 
where

$$
\begin{aligned}
\Omega(\mu) & \equiv\left[\Lambda \omega_{0}+1\right] \omega_{1} \\
& =\left[\Lambda \exp \left(-\mu^{\alpha}\right)+1\right]\left[1-\exp \left(-\mu^{\alpha}\right)\right]
\end{aligned}
$$

From these equations, it is clear that variation in $p$ and $\mu$ permits us to separately identify $r$ and $\Omega(\mu)$, and then variation in $\mu$ permits us to separately identify $\Lambda$ and $\alpha .^{22}$ Thus, given sufficient variation in premiums and claim rates for a fixed $Z$, the preference parameters are identified.

We now argue that our data indeed contains significant variation in premiums and claim rates even for a fixed $Z$. For each coverage, a household's claim rates are determined by factors beyond its vector of household characteristics $Z$. As described in Section 2.3, the household's predicted claim rate depends on a vector of observables $X \supset Z$. More importantly, the household's menu of premiums is determined by factors beyond those that determine the household's claim rate. As explained in Section 2.2, the household's menu of premiums is a function not only of observables $X$ but also other coverage-specific variables, such as state regulations, the company's tier and deductible factors (which are the same for all households), and various discount programs. Consequently, there is variation in premiums that is not driven by the variation in claim rates or in $Z$, and the variation in claim rates does not arise solely because of the variation in $Z .^{23}$ In the case of auto collision coverage, for example, regressions of premiums and predicted claim rates on $Z$ yield coefficients of determination of 0.13 and 0.34 , respectively, and the correlation coefficient between benchmark premiums (premiums for coverage with a $\$ 500$ deductible) and predicted claim rates is $0.35 .^{24}$

In addition to the significant variation in premiums and claim rates within a coverage, our data also contain significant variation in premiums and claim rates across coverages. A key feature of our data is that for each household we observe deductible choices for three coverages, and even for a fixed $Z$ (and, in fact, even for a fixed $X$ ), there is significant

\footnotetext{
${ }^{22}$ This holds even if $r$ is zero and the right-hand side of equation (7) collapses to $\left(p_{b}-p_{a}\right)+\Omega(\mu)(b-a)$.

${ }^{23}$ Moreover, it is safe to assume that, for a fixed $Z$, the variation in premiums and claims rates is exogenous to the households' risk preferences. Indeed, several of the variables in $X \backslash Z$ (such as distance to hydrant and territory code (which the company bases on actuarial risk factors, such as weather patterns and wildlife density)), as well as the additional variables that determine premiums (such as state law and the company's rating plan), are undoubtedly exogenous to the households' risk preferences. Even if these variables were not wholly exogenous, it is not clear that this would bias our results in favor of nonlinear probability weighting and against standard risk aversion and loss aversion.

${ }^{24}$ The corresponding coefficients for auto comprehensive and home are even lower. In the case of auto comprehensive, the coefficients of determination are 0.07 and 0.31 , and the correlation coefficient is 0.15 . In the case of home, the coefficients of determination are 0.04 and 0.12 , and the correlation coefficient is 0.24 .
} 
variation in premiums and claim rates across the three coverages. Indeed, even if the withincoverage variation in $p$ and $\mu$ was insufficient in practice, we still might be able to separately identify $r, \Lambda$, and $\alpha$ using across-coverage variation.

\section{Estimation Results}

This section presents the results of our main analysis, including our benchmark estimates. It also presents extensions in which we endeavour to account for wealth and for unobserved heterogeneity in claim rates.

\subsection{Benchmark Results}

In our initial specification, we assume no heterogeneity $\left(Z_{i}\right.$ includes only a constant). We refer to this specification as Model 1. The estimates for standard risk aversion and loss aversion are both effectively zero - the estimate for $r$ is $3.1 \cdot 10^{-10}$ (standard error: $8.7 \cdot 10^{-9}$ ) and the estimate for $\Lambda$ is $5.8 \cdot 10^{-7}$ (standard error: $1.6 \cdot 10^{-5}$ ). By contrast, the estimated probability weighting parameter $(\alpha)$ is 0.68 (standard error: 0.0027 ) which, as we illustrate below, is economically large. While Model 1 is an oversimplification, it provides a clear illustration of our main conclusion: nonlinear probability weighting plays the dominant role in explaining the households' deductible choices.

Table 5 reports the estimates for our benchmark specification, which we label Model 2. Model 2 permits the preference parameters to depend on household characteristics. Specifically, the covariates include a constant and all of the variables in Table $1,{ }^{25}$ except for home value. We view home value primarily as a proxy for wealth, and thus we introduce it below when we endeavor to account for wealth. The top panel presents the coefficient estimates for the covariates, $\widehat{\beta}_{r}, \widehat{\beta_{\Lambda}}$, and $\widehat{\beta_{\alpha}}$, as well as the estimate of the scale of choice noise, $\widehat{\sigma}$. These estimates imply nontrivial heterogeneity in the underlying preference parameters and nonzero choice noise. The bottom panel presents the mean and median of the fitted values for the preference parameters, $r, \Lambda$, and $\alpha$. For $r$, the median estimate is effectively zero, though the mean estimate is somewhat larger at approximately $3.0 \cdot 10^{-5} \cdot{ }^{26}$ While this implies nontrivial standard risk aversion, it does not imply "absurd" risk aversion in the sense of Rabin (2000). For a household with wealth of $\$ 100,000$, for example, a coefficient of absolute risk aversion of $3.0 \cdot 10^{-5}$ implies a coefficient of relative risk aversion of 3 , a

\footnotetext{
${ }^{25}$ Each variable $z$ is normalized as $(z-$ mean $(z)) / \operatorname{stdev}(z)$.

${ }^{26}$ This is because certain types of households - particularly young, unmarried households - have larger estimated standard risk aversion. Nevertheless, of the 4170 households in the core sample, only 8 are assigned $r>0.001$ and only 238 are assigned $r>0.0001$.
} 
magnitude that many economists would consider plausible. For $\Lambda$, the mean and median estimates are both effectively zero, suggesting that loss aversion plays little to no role in explaining the data. For $\alpha$, the mean and median estimates are both approximately 0.7 , which implies pronounced nonlinear probability weighting.

\section{TABLE 5}

\subsubsection{Statistical Significance}

A likelihood ratio test rejects at the 1 percent level both the null hypotheses of standard risk neutrality $(r=0)$ and the null hypothesis of linear probability weighting $(\alpha=1)$, suggesting that both standard risk aversion and nonlinear probability weighting play a statistically significant role in deductible choices. By contrast, a likelihood ratio test fails to reject the null hypothesis of net loss neutrality $(\Lambda=0)$, which is consistent with loss aversion playing little to no role. To test the relative statistical importance of standard risk aversion, loss aversion, and nonlinear probability weighting, we also estimate restricted models and perform Vuong (1989) model selection tests. ${ }^{27}$ We find that the model with nonlinear probability weighting alone is "better" (at the 1 percent level) than (i) a model with standard risk aversion alone, (ii) a model with loss aversion alone, and (iii) a model with both standard risk aversion and loss aversion.

\subsubsection{Economic Significance}

To give a sense of the economic significance of our benchmark estimates for standard risk aversion, loss aversion, and nonlinear probability weighting, we present the following "backof-the-envelope" calculations in Table 6. For selected claim rates $\mu$, column (1) contrasts the probability of experiencing one claim, $\mu_{1}=\mu \exp (-\mu)$, with the associated decision weight, $\omega_{1} \equiv \pi\left(\mu_{1}+\mu_{0}\right)-\pi\left(\mu_{0}\right)$, for the case where $\alpha=0.7$. For instance, when the probability of one claim is 2.0 percent, the decision weight is 6.0 percent; when the probability of one claim is 6.5 percent, the decision weight is 13.0 percent; and when the probability of one claim is 12.9 percent, the decision weight is 19.3 percent.

Columns (2)-(9) display, for selected claim rates $\mu$ and various preference parameter combinations, the dollar amount $\Delta$ that would make a household with the utility function

\footnotetext{
${ }^{27}$ Vuong's (1989) test allows one to select between two nonnested models on the basis of which best fits the data. Neither model is assumed to be correctly specified. Vuong (1989) shows that testing whether one model is significantly closer to the truth (its loglikelihood value is significantly greater) than another model amounts to testing the null hypothesis that the loglikelihoods have the same expected value.
} 
in equation (5) indifferent between the following two deductible lotteries:

$$
\begin{aligned}
L_{1000} & =\left(-\$ 200, \mu_{0} ;-\$ 200-\$ 1000, \mu_{1} ;-\$ 200-\$ 2000, \mu_{2}\right) ; \text { and } \\
L_{500} & \left.\left.=\left(-(\$ 200+\Delta), \mu_{0} ;-(\$ 200+\Delta)-\$ 500\right), \mu_{1} ;-(\$ 200+\Delta)-\$ 1000\right), \mu_{2}\right) .
\end{aligned}
$$

Lottery $L_{1000}$ represents coverage with a $\$ 1000$ deductible and a premium of $\$ 200$, and $L_{500}$ represents a policy with a $\$ 500$ deductible and a premium of $\$ 200+\Delta$. Thus, $\Delta$ corresponds to the household's maximum willingness to pay $(W T P)$, in terms of excess premium above $\$ 200$, to reduce its deductible from $\$ 1000$ to $\$ 500$.

As a benchmark, column (2) reports $W T P$ for a standard risk-neutral household, with $r=0, \Lambda=0$, and $\alpha=1$. Column (3) reports $W T P$ for a household with $r=0, \Lambda=0$, and $\alpha=0.7$. It illustrates that the mean estimated degree of nonlinear probability weighting, by itself, generates substantial aversion to risk, in the sense that the household's WTP is approximately two to three times larger than a standard risk-neutral household. For a household with a claim rate of 7 percent, for example, moving from $\alpha=1$ to $\alpha=0.7$ increases the household's WTP from $\$ 35$ to $\$ 79$.

Columns (4) and (5) reports $W T P$ for a household with $r=0.00003, \Lambda=0$, and either $\alpha=1$ (column (4)) or $\alpha=0.7$ (column (5)). Together, they illustrate that the mean estimated degree of standard risk aversion has little per se effect on the household's WTP. For the household with a claim rate of 7 percent, for instance, moving from $r=0$ to $r=$ 0.00003 increases $W T P$ by less than one dollar when $\alpha=1$ and less than two dollars when $\alpha=0.7$. In other words, columns (4) and (5) illustrate that, at our benchmark estimate, standard risk aversion plays a small role in explaining the aversion to risk manifested in the households' deductible choices.

In order to establish certain benchmarks for later results, columns (6) and (7) report $W T P$ when the degree of standard risk aversion is $r=0.0001$ and $r=0.001$, respectively (i.e., one and two orders of magnitude larger than our benchmark estimate), and column (8) reports $W T P$ when the degree of net loss aversion is $\Lambda=0.02$ (which is as large as we ever find when we also allow for nonlinear probability weighting). In all three columns $\alpha=0.7$. Increasing the degree of standard risk aversion to $r=0.0001$ marginally increases the household's WTP (for the household with $\mu=0.07, W T P$ increases from $\$ 79$ to $\$ 85$ ), whereas increasing the degree of standard risk aversion to $r=0.001$ substantially increases the household's WTP (for the household with $\mu=0.07, W T P$ increases from $\$ 79$ to $\$ 123$ ). Increasing the degree of net loss aversion to $\Lambda=0.02$ has little effect on the household's $W T P$ (for the household with $\mu=0.07, W T P$ increases from $\$ 79$ to $\$ 82$ ).

\section{TABLE 6}




\subsubsection{Predicting Households' Deductible Choices}

For each household $i$ and coverage $j$, the parameter estimates $\widehat{\theta}$ imply a probability that the household's choice $D_{i j}$ for such coverage corresponds to the deductible $d$ we observe in the data (i.e., $\operatorname{Pr}\left(D_{i j}=d \mid \Gamma_{i j}, \widehat{\theta}\right)$ from Section 3.3). These choice probabilities provide a sense of how the model performs in terms of predicting the households' deductible choices. Table 7 describes these choice probabilities for each coverage. As a baseline, row (1) reports the choice probabilities assuming households chose their deductibles uniformly at random. ${ }^{28}$

Row (2) reports the average of the model predicted choice probabilities across all households. Rows (3)-(7) provide a sense of how the model performs for different deductibles. In each row, the table reports the average choice probability among households who chose the indicated deductible. The model performs best in explaining the more common, intermediate deductible choices, while it performs less well in explaining the less common, extreme deductible choices.

Finally, rows (8) and (9) report the average choice probabilities for two restricted models. Row (8) reports the average choice probabilities for a model with only nonlinear probability weighting (i.e., when we estimate the model restricting $r=\Lambda=0$ ), while row (9) reports the average choice probabilities for a model with only standard risk aversion (i.e., when we restrict $\Lambda=0$ and $\alpha=1$ ). Comparisons with row (2) reveals that the model with only nonlinear probability weighting performs almost as well as the full model, whereas the full model comfortably outperforms the model with only standard risk aversion.

\section{TABLE 7}

\subsection{Accounting for Wealth}

As noted in Section 3.2, we do not directly observe the wealth of the households in the data. Economists generally believe, however, that standard risk aversion depends on wealth. In our benchmark results, we deal with this issue by estimating a local approximation of absolute risk aversion. In this section, we endeavor to account for household wealth by using home value as a proxy.

In Model 3, we take a naive, reduced-form approach and merely add home value to the vector of observables, $Z_{i}$, upon which a household's preference parameters depend. That is, Model 3 effectively assumes that a household's intrinsic utility function depends on its wealth.

\footnotetext{
${ }^{28}$ For auto collision, there are five deductible levels, and so uniformly random choice would yield choice probabilities of 20 percent for each deductible option. For auto comprehensive and home, there are six deductible levels, and so uniformly random choice would yield choice probabilities of 16.7 percent for each deductible option.
} 
However, economists typically do not assume that utility functions depend on wealth, but rather that utility is a function of wealth (i.e., wealth is the domain of the utility function). Hence, Model 3 is perhaps a misspecified model.

In Models 4 and 5, we take a structural approach, in which we assume constant relative risk aversion (CRRA) utility, i.e., $u(w)=w^{1-\rho} /(1-\rho), \rho>0$. In the CRRA specification, $\rho$ is the coefficient of relative risk aversion, and thus $\rho=w \cdot r$. We allow $\rho$ to depend on household characteristics, $Z_{i}$, assuming (as above) $\ln \rho=\beta_{\rho} Z_{i}$, and we take home value as a proxy for wealth, to wit $r=\rho$ (home value) in equation (5). In Model 4 , we estimate this specification without also including home value in $Z_{i}$; that is, we assume that the preference parameters do not depend on home value other than through the relationship $r=\rho /$ (home value). However, because in addition to being a proxy for wealth, home value might also be a signal of household type, in Model 5 we also include home value in $Z_{i}$. Model 5 reflects our preferred approach to accounting for wealth.

Table 8 reports the mean and median of the fitted values for the preference parameters for Models 3, 4, and 5. ${ }^{29}$ For comparison, the first panel restates the benchmark estimates from Model 2. The second panel reports the estimates from Model 3. They are very similar to the benchmark estimates, except in the case of standard risk aversion, where the mean estimate is an order of magnitude larger, at approximately $3.8 \cdot 10^{-4}$, and the median estimate now is the same order of magnitude as the mean estimate, at approximately $2.5 \cdot 10^{-4} .{ }^{30}$ But again, we believe this is a misspecified model. The third and fourth panels report the estimates for Models 4 and 5. The estimates for both models are nearly identical to the benchmark estimates; the only substantive difference is that the mean and median estimates for standard risk aversion are roughly twice as large as the benchmark estimates, although they have the same order of magnitude. In terms of the direct impact of home value in Model 5, the coefficient estimates (which are reported in Table A.8 in the Appendix) suggest that home value does not have a direct impact on the degree of standard risk aversion - the effect is fully captured by the relationship $r=\rho$ /(home value)-but that it does have a positive and statistically significant relationship with the degree of nonlinear probability weighting, suggesting that owning a more expensive home is associated with being closer to linear probability weighting.

\section{TABLE 8}

\footnotetext{
${ }^{29}$ For the sake of brevity, Table 8 does not report the coefficient estimates for the covariates. The complete results, however, are reported in Tables A.6 through A.8 in the Appendix.

${ }^{30}$ As reported in Table A.6, we also find that standard risk aversion declines with home value, which is consistent with the usual economic assumption that absolute risk aversion declines with wealth.
} 


\subsection{Accounting for Unobserved Heterogeneity in Claim Rates}

In our main analysis, we assign to each household in the core sample a predicted claim rate $\widehat{\mu}$ for each coverage. While this approach allows for heterogeneity in claim rates based on observable characteristics, it does not permit unobserved heterogeneity. Such unobserved heterogeneity is potentially important, however, because it might help explain why observationally equivalent households choose different deductibles. In order to account for unobserved heterogeneity in claim rates, we expand our approach and assign to each household its predicted distribution of claim rates for each coverage.

More specifically, in Section 3 we derive a household's choice probability as a function of the household's (latent) true claim rate $\mu$. In our benchmark analysis, we assume that, for each coverage, the household's true claim rate corresponds to its predicted claim rate $\widehat{\mu}$, which we calculate using the estimates from the claim rate regression for such coverage. We then construct the likelihood function using the choice probabilities for all households; in particular, we use the regression estimates to calculate the expected claim rate conditional on the household's observables. Of course, the claim rate regressions yield not only the conditional expectation, but also the conditional distribution of claim rates. Hence, we can use the regression estimates to assign to each household not just a predicted claim rate $\widehat{\mu}$, but also predicted claim rate distribution $\widehat{F}(\mu)$. We can then construct the likelihood function by integrating over $\widehat{F}(\mu) .{ }^{31}$

Table 9 reports the mean and median of the preference parameter estimates for Models 2 and 5 (relabeled as Models $2 \mathrm{u}$ and $5 \mathrm{u}$ ) when we allow for unobserved heterogeneity in this way. ${ }^{32}$ The main message is roughly the same. Loss aversion is nonexistent. Nonlinear probability weighting is statistically and economically significant, although it is somewhat smaller in magnitude - the mean and median of the fitted values of $\alpha$ are approximately 0.8 (rather than 0.7). Standard risk aversion is statistically significant, but now is economically significant as well. The mean and median fitted values of $r$ are approximately $1.0 \cdot 10^{-3}$ and $5.7 \cdot 10^{-4}$, respectively, in Model $2 \mathrm{u}$ and approximately $7.3 \cdot 10^{-4}$ and $2.3 \cdot 10^{-4}$, respectively, in Model 5u. As Table 6 suggests, standard risk aversion of this order of magnitude implies appreciable aversion to risk.

\section{TABLE 9}

\footnotetext{
${ }^{31}$ We compute this integral using the Gauss-Laguerre quadrature method.

${ }^{32}$ The complete results, with the coefficient estimates for the covariates, are reported in Tables A.9 and A.10 in the Appendix.
} 


\section{$5 \quad$ Sensitivity Analysis}

Our analysis in Section 4 yields a clear main message: nonlinear probability weighting plays the most important role in explaining the households' deductible choices. More specifically, only nonlinear probability weighting is consistently statistically and economically significant; standard risk aversion is consistently statistically significant but is economically significant only in a subset of specifications, and loss aversion is consistently estimated to be nonexistent. In this section, we investigate the sensitivity of these results to our modeling assumptions. In general, we find that the results are quite robust to a variety of alternative assumptions. The main result that varies across specifications is the economic significance of standard risk aversion. To conserve space, we only summarize the results of the sensitivity analysis below. The complete results are available in the Appendix (Tables A.11 through A.23).

\subsection{Form of Probability Weighting}

As noted in Section 3.1, we incorporate nonlinear probability weighting into the model by (i) adopting the rank-dependent approach of Quiggin (1982), which contemplates a transformation of the decumulative distribution, and (ii) using the one-parameter probability weighting function proposed by Prelec (1998). In this section, we check the sensitivity of our results to a transformation of the cumulative distribution and to other probability weighting functions.

In their cumulative prospect theory paper, Tversky and Kahneman (1992) propose a rank-dependent approach to nonlinear probability weighting that contemplates a transformation of the decumulative distribution for gains and the cumulative distribution for losses. The point of their approach is that extreme outcomes (the largest gains and the largest losses) are what get overweighted. In the case of our deductible lotteries, $L_{d}=$ $\left(-p_{d}, \mu_{0} ;-p_{d}-d, \mu_{1} ;-p_{d}-2 d, \mu_{2}\right)$, which involve only losses, their approach implies the following decision weights:

$$
\begin{aligned}
\omega_{2} & \equiv \pi\left(\mu_{2}\right) \\
\omega_{1} & \equiv \pi\left(\mu_{1}+\mu_{2}\right)-\pi\left(\mu_{2}\right) \\
\omega_{0} & \equiv 1-\pi\left(\mu_{1}+\mu_{2}\right) .
\end{aligned}
$$

When we estimate Models 2 and 5 using these decision weights (and the Prelec (1998) oneparameter probability weighting function), the mean and median of the estimated preference parameters are essentially unchanged, except that mean estimate for standard risk aversion in Model 5 is roughly half the magnitude (and the roughly same as in Model 2).

Tversky and Kahneman (1992) also propose an alternative one-parameter probability 
weighting function: $\pi(\mu)=\mu^{\delta} /\left[\mu^{\delta}+(1-\mu)^{\delta}\right]^{1 / \delta}$. When we estimate Model 2 using their probability weighting function (and, as they suggest, the cumulative form of rank dependence), our main message is much the same. Nonlinear probability weighting is statistically and economically significant - the mean and median estimates of $\delta$ are approximately 0.44 and 0.56, respectively, both of which are somewhat smaller (more nonlinear) than Tversky and Kahneman's median estimate of 0.69. (Figure 1 depicts the Tversky and Kahneman (1992) function for $\delta=0.5$ and $\delta=0.69$, as well as the Prelec (1998) function for $\alpha=0.7$.) Standard risk aversion is statistically significant but economically insignificant - the mean estimate is $8.3 \cdot 10^{-5}$ and the median estimate is effectively zero. The only apparent difference is that the mean estimate for the coefficient of net loss aversion is approximately 0.02 (though the median estimate still is zero). As Table 6 illustrates, however, loss aversion of this magnitude is not economically significant.

\section{FIGURE 1}

Both the Prelec (1998) and Tversky and Kahneman (1992) probability weighting functions have the feature of implying hypersensitivity to small probability changes near the extremes of the probability scale. It is not clear, however, whether there is good evidence of such hypersensitivity. Because our data contain many observations of small claim probabilities, we also consider a linear probability weighting function, $\pi(\mu)=\alpha \mu+(1-\alpha) / e$. Note that $\pi(\mu)$ intersects the 45 degree line at $\mu=1 / e$ (with $\pi(\mu)>\mu$ for $\mu<1 / e$ and $\pi(\mu)<\mu$ for $\mu>1 / e$ ) for all values of $\alpha$; this makes it comparable to the Prelec (1998) one-parameter specification, which also intersects the the 45 degree line at $1 / e$ for all values of $\alpha$. When we estimate Model 2 using this probability weighting function (and, as in our benchmark analysis, the decumulative form of rank dependence), the preference parameter estimates are effectively identical to the benchmark estimates.

Finally, each of the foregoing probability weighting functions captures two featuresoverweighting of small probabilities and insensitivity to probability changes - with a single parameter. For this reason, we also consider the two-parameter probability weighting function suggested by Lattimore et al. (1992), $\pi(\mu)=a \mu^{\delta} /\left[a \mu^{\delta}+(1-\mu)^{\delta}\right]$, where roughly $a$ captures overweighting and $\delta$ captures insensitivity. ${ }^{33}$ When we estimate Model 2 using this specification (and the decumulative form of rank dependence), our main message emerges yet again: nonlinear probability weighting is statistically and economically significant (the estimates for $a$ and $\delta$ are roughly 5 and 0.2 , respectively), standard risk aversion is statisti-

\footnotetext{
${ }^{33}$ This function was used earlier by Goldstein and Einhorn (1987). As Gonzalez and Wu (1999) demonstrate, it is equivalent to specifying that the log-odds ratio of the weighted probability be a linear function of the log-odds ratio of the true probability.
} 
cally significant but economically small (the mean estimate is approximately $8.6 \cdot 10^{-5}$ and the median estimate is zero), and loss aversion is nonexistent.

In light of the robustness of our results to the form of probability weighting, the remainder of our sensitivity analysis follows our main analysis and uses the decumulative form of rank dependence and the Prelec (1998) one-parameter probability weighting function.

\subsection{CARA Utility}

In our main analysis, we account for initial wealth by using a second-order Taylor expansion of the intrinsic utility function. Here we take an alternative approach: we assume constant absolute risk aversion (CARA) utility, $u(w)=-\exp (-r w)$, in which case initial wealth is irrelevant. When we estimate Model 3 with CARA utility — which, with CARA utility, is the analogue for our Model 5 (our preferred approach to accounting for wealth) - our main message is roughly the same. Loss aversion is nonexistent. Nonlinear probability weighting is statistically and economically significant, although it is smaller in magnitude (more linear) the mean and median of the fitted values of $\alpha$ are approximately 0.9 and 0.8 , respectively. Standard risk aversion is statistically significant, but now is economically significant as wellthe mean and median fitted values of $r$ are $7.1 \cdot 10^{-4}$ and $6.8 \cdot 10^{-4}$, respectively. As between Model 3 with CARA utility and Model 5, however, a Vuong (1989) test decidedly selects Model 5 as the one which best fits the data.

\subsection{Maximum Number of Claims}

Our main analysis permits that a household may have zero, one, or two claims. Given the importance of nonlinear probability weighting in our results, one might worry that allowing for the low probability event of experiencing two claims is having undue influence on our results. Hence, we estimate Models 2 and 5 permitting households to have at most one claim. The results tell the same basic story. The only noteworthy difference is that the mean estimate for the coefficient of net loss aversion in Model 5 is roughly 0.001 (though the median estimate still is zero), but this is not economically significant.

\subsection{Extreme Deductibles}

Table 2 reveals that, for each coverage, the vast majority of households in the core sample choose intermediate deductibles: 92.3 percent of households choose a deductible of $\$ 200$, $\$ 250$, or $\$ 500$ in auto collision; 87.1 percent of households choose a deductible of $\$ 200, \$ 250$, or $\$ 500$ in auto comprehensive; and 97.5 percent of households choose a deductible of $\$ 250$, 
$\$ 500$, or $\$ 1000$ in home. Given these choice patterns, one might worry that households do not really consider the more extreme deductible options, which might bias our estimates. ${ }^{34}$ To address this concern, we estimate Model 2 under the following conditions: (i) we restrict the set of deductible options to $\{\$ 200, \$ 250, \$ 500\}$ for each of the auto coverages and to $\{\$ 250, \$ 500, \$ 1000\}$ for home coverage; and (ii) for each coverage, if a household's actual deductible choice is outside the restricted choice set, we assign to the household the deductible option from the restricted choice set that is closest to their actual deductible choice. The results are essentially the same. The only appreciable difference is that mean and median estimates for standard risk aversion are somewhat larger: roughly $1.1 \cdot 10^{-4}$ (which is borderline economically significant) and $9.4 \cdot 10^{-6}$ (which is not economically significant), respectively.

\subsection{Coverage-Specific Analysis}

As noted in Section 3.3, our main analysis estimates risk preferences using combined data for all three coverages. We believe this is the best approach because it enhances the variation in premiums and claim rates. Nevertheless, we also investigate whether the benchmark results are robust to estimating the model separately for each coverage. When we estimate Model 2 separately for each coverage, the main message is roughly the same. For auto comprehensive coverage, the estimates for loss aversion and nonlinear probability weighting nearly correspond to the benchmark estimates, though there is economically significant standard risk aversion (the mean and median estimates for $r$ are approximately $1.7 \cdot 10^{-3}$ and $1.4 \cdot 10^{-3}$, respectively). For home coverage, the estimates for nonlinear probability weighting are almost identical to the benchmark estimates, while there is a little more standard risk aversion (the mean and median estimates are approximately $7.5 \cdot 10^{-5}$ and $1.7 \cdot 10^{-5}$, respectively) and perhaps some loss aversion (the mean estimate for $\Lambda$ is approximately 0.006 , but the median estimate still is zero), though both are economically insignificant. For auto collision coverage, loss aversion is nonexistent, but there is more (and economically significant) standard risk aversion (the mean and median estimates for $r$ are roughly $1.3 \cdot 10^{-3}$ and $1.2 \cdot 10^{-3}$, respectively) and less nonlinear probability weighting (the mean and median estimates $\alpha$ are both roughly 0.9 ).

Even when we estimate risk preferences using combined data from all three coverages, a second way to allow for coverage-specific effects is to permit coverage-specific choice noise

\footnotetext{
${ }^{34}$ For instance, when a household chooses a $\$ 200$ deductible in auto comprehensive, we are using the fact that it did not choose a $\$ 50$ deductible to infer an upper bound on its aversion to risk. But if the household in fact does not even consider the $\$ 50$ deductible as an option, our inference would be invalid. Similarly, when a household chooses a $\$ 1000$ deductible in home, we are using the fact that it did not choose a $\$ 5000$ deductible to infer a lower bound on its aversion to risk. Again, if the household in fact does not even consider the $\$ 5000$ deductible as an option, our inference would be invalid.
} 
(our main analysis assumes that choice noise $(\sigma)$ does not vary across coverages). When we estimate Model 2 with coverage-specific choice noise, the results are nearly identical, except that there is a little more standard risk aversion (the mean and median fitted values of $r$ are approximately $1.1 \cdot 10^{-4}$ and $7.0 \cdot 10^{-5}$, respectively).

\section{Discussion}

We develop a structural model of risky choice that incorporates standard risk aversion (concave utility over final wealth), loss aversion, and nonlinear probability weighting, and we estimate the model using data on households' deductible choices in auto and home insurance. We find that nonlinear probability weighting plays the most important role in explaining the data, while standard risk aversion plays a small role and loss aversion plays little to no role. Insofar as they are generalizable, our results suggest that risk preferences are shaped first and foremost by how one evaluates risk and only second by how one evaluates outcomes.

Perhaps the main takeaway of the paper is that economists should pay greater attention to the question of how people evaluate risk. Prospect theory incorporates two key features: a value function that describes how people evaluate outcomes and a probability weighting function that describes how people evaluate risk. The behavioral economics literature, however, has focused primarily on the value function, and there has been relatively little focus on probability weighting. ${ }^{35}$ In light of our work, as well as the work discussed in Section 1 that reaches a similar conclusions using different methods (Bruhin et al., forthcoming; Snowberg and Wolfers, forthcoming; Kliger and Levy 2009), it seems clear that the literature ought to reevaluate its focus. ${ }^{36}$

That said, it is worth highlighting certain limitations of our analysis. An important limitation is that, while our analysis clearly indicates that the main "action" lies in how people evaluate risk, it does not enable us to say whether households are engaging in nonlinear probability weighting per se - i.e., they know the probabilities but weight them nonlinearlyor whether their subjective beliefs simply do not correspond to the objective probabilities. Relatedly, it is not clear that nonlinear probability weighting is the best way to model how people evaluate risk. Indeed, there are a variety of other models that take different approaches - the leading examples include models of ambiguity averse preferences (e.g.,

\footnotetext{
${ }^{35}$ Two prominent review papers - an early paper that helped set the agenda for behavioral economics (Rabin 1998) and a recent paper that surveys the current state of empirical behavioral economics (DellaVigna 2009) _ contain almost no discussion of probability weighting. The behavioral finance literature has paid a more attention to probability weighting (see, e.g., Barberis and Huang 2008; Barberis 2010)

${ }^{36}$ Indeed, Prelec (2000) conjectured that "probability nonlinearity will eventually be recognized as a more important determinant of risk attitudes than money nonlinearity."
} 
Gilboa and Schmeidler 1989; Schmeidler 1989; Klibanoff et al. 2005). An important avenue of future research, therefore, is to investigate different accounts of how people evaluate risk and uncertainty.

A second limitation is that our analysis relies exclusively on insurance deductible choices, and it is unclear the extent to which our conclusions generalize to other choices or settings. While we suspect that our main message would resonate in many domains beyond insurance deductible choices, it is evident that our estimated model would not perform well in certain contexts. In particular, people often display aversion to risk in 50-50 positive expected value gambles - e.g., people frequently reject gambles with a 50 percent chance to win $\$ 110$ and a 50 percent chance to lose $\$ 100$. It seems clear that nonlinear probability weighting does not explain such aversion to risk.

A third limitation pertains to the way we account for observationally equivalent households choosing different deductibles. As described in Section 3.2, we specify a random utility model with additively separable choice noise. There are alternative approaches, however, including the random error (or tremble) model (Harless and Camerer 1994) and the random preference model (Loomes and Sugden 1995), though neither is clearly superior to ours (Loomes and Sugden 1998; Loomes et al. 2002). It would be useful nevertheless to explore these and perhaps other approaches in future work, particularly in light of recent work on the stability of risk preferences (Barseghyan et al., forthcoming; Einav et al. 2010).

It is also worth clarifying our conclusion that loss aversion plays little to no role in explaining the households' deductible choices. What we find is little to no role for KöszegiRabin loss aversion - that is, loss aversion wherein gains and losses are defined relative to recent expectations, which in turn are determined by the chosen option. We find this result intriguing, because Kőszegi and Rabin (2007) and Sydnor (forthcoming) hypothesize that KR loss aversion is implicated in insurance deductible choices. Nonetheless, our analysis does not contradict the original, "status quo" loss aversion proposed by Kahneman and Tversky (1979) - that is, loss aversion wherein gains and losses are defined relative to initial wealth. In the context of insurance deductible choices, because all outcomes are losses relative to initial wealth, status quo loss aversion is inapposite. However, it is probably the best explanation for aversion to 50-50 positive expected value gambles.

Finally, we highlight that our benchmark estimates are immune to the Rabin critique (Rabin 2000). Rabin uses a calibration argument to demonstrate the inability of the standard expected utility model to explain appreciable aversion to gambles with moderate stakese.g., rejecting a gamble involving equal chances to win $\$ 110$ and lose $\$ 100$-because it implies an "absurd" degree of risk aversion when the stakes are increased by one or two orders of 
magnitude. ${ }^{37}$ Ex ante (before confronting the data) our analysis could have yielded absurdly high levels of risk aversion-i.e., in our estimation procedure, the parameter space allowed for any degree of risk aversion. As we demonstrate in Section 4, however, our benchmark estimate for standard risk aversion implies a plausibly small level of aversion to risk (both in terms of the implied coefficient of relative risk aversion and the implied willingness to pay for lower deductibles). At the same time, the degree of probability weighting is independent of stakes, and thus increases in stakes have little effect on risk attitudes. ${ }^{38}$ We hope to pursue this theme in future research by exploiting the fact that our data set records both deductible choices, which involve moderate stakes, and liability limit choices, which involve stakes that are orders of magnitude larger.

\section{References}

Barberis, N. (2010): "A Model of Casino Gambling," Mimeo, Yale University, http://badger.som.yale.edu/faculty/ncb25/gb23d.pdf.

Barberis, N. And M. Huang (2008): "Stocks as Lotteries: The Implications of Probability Weighting for Security Prices," American Economic Review, 98, 2066-2100.

Barseghyan, L., J. Prince, and J. C. Teitelbaum (Forthcoming): "Are Risk Preferences Stable Across Contexts? Evidence from Insurance Data," American Economic Review.

Bruhin, A., H. Fehr-Duda, and T. Epper (Forthcoming): "Risk and Rationality: Uncovering Heterogeneity in Probability Distortion," Econometrica.

Choi, S., R. Fisman, D. Gale, and S. Kariv (2007): "Consistency and Heterogeneity of Individual Behavior under Uncertainty," American Economic Review, 97, 1921-1938.

Cicchetti, C. J. And J. A. Dubin (1994): "A Microeconometric Analysis of Risk Aversion and the Decision to Self-Insure," Journal of Political Economy, 102, 169-186.

Cohen, A. And L. Einav (2007): "Estimating Risk Preferences from Deductible Choice," American Economic Review, 97, 745-788.

\footnotetext{
${ }^{37}$ Sydnor (forthcoming) applies the Rabin critique to argue that the degree of standard risk aversion implied by the observed deductible choices in his data set is implausibly large.

${ }^{38}$ For instance, if there were no standard risk aversion and no loss aversion, then even with probability weighting, the certainty equivalent of a lottery would merely increase proportionally with the stakes (if all outcomes in the lottery are multiplied by $m$, then the certainty equivalent is simply $m$ times larger).
} 
Della Vigna, S. (2009): "Psychology and Economics: Evidence from the Field," Journal of Economic Literature, 47, 315-372.

Dunham, W. B., ed. (2009): New Appleman New York Insurance Law, Second Edition, New Providence, NJ: LexisNexis.

Einav, L., A. Finkelstein, I. Pascu, and M. R. Cullen (2010): "How General are Risk Preferences? Choice under Uncertainty in Different Domains," Working Paper 15686, NBER.

Gilboa, I. And D. Schmeidler (1989): "Maxmin Expected Utility with Non-Unique Prior," Journal of Mathematical Economics, 18, 141-153.

Goldstein, W. M. and H. J. Einhorn (1987): "Expression Theory and the Preference Reversal Phenomena," Psychological Review, 94, 236-254.

Gonzalez, R. and G. Wu (1999): "On the Shape of the Probability Weighting Function," Cognitive Psychology, 38, 129-166.

Grgeta, E. (2003): "Estimating Risk Aversion: Comment on Cicchetti and Dubin 1994," Mimeo, http://www.grgeta.com/edi/grgeta-CD_comment.pdf.

Harless, D. W. and C. F. Camerer (1994): "The Predictive Utility of Generalized Expected Utility Theories," Econometrica, 62, 1251-2189.

Hey, J. D. And C. Orme (1994): "Investigating Generalizations of Expected Utility Theory Using Experimental Data," Econometrica, 62, 1291-1326.

Jullien, B. and B. Salanié (2000): "Estimating Preferences under Risk: The Case of Racetrack Bettors," Journal of Political Economy, 108, 503-530.

Kahneman, D. and A. Tversky (1979): "Prospect Theory: An Analysis of Decision under Risk," Econometrica, 47, 263-291.

Köszegi, B. And M. Rabin (2006): "A Model of Reference-Dependent Preferences," Quarterly Journal of Economics, 121, 1133-1166.

- (2007): "Reference-Dependent Risk Attitudes," American Economic Review, 97, $1047-1073$.

Klibanoff, P., M. Marinacci, And M. Mukerui (2005): "A Smooth Model of Decision Making under Ambiguity," Econometrica, 73, 1849-1892. 
Kliger, D. And O. Levy (2009): "Theories of Choice under Risk: Insights from Financial Martkets," Journal of Economic Behavior and Organization, 71, 330-346.

Lattimore, P. K., J. R. Baker, and A. D. Witte (1992): "The Influence of Probability on Risky Choice: A Parametric Examination," Journal of Economic Behavior and Organization, 17, 377-400.

Loomes, G., P. G. Moffatt, and R. Sugden (2002): "A Microeconometric Test of Alternative Stochastic Theories of Risky Choice," Journal of Risk and Uncertainty, 24, $103-130$.

Loomes, G. And R. Sugden (1995): "Incorporating a Stochastic Element into Decision Theories," European Economic Review, 39, 641-648.

- (1998): "Testing Different Stochastic Specifications of Risky Choice," Economica, $65,581-598$.

Matzkin, R. L. (1991): "Semiparametric Estimation of Monotone and Concave Utility Functions for Polychotomous Choice Models," Econometrica, 59, 1315-1327.

McFadden, D. (1974): "Conditional Logit Analysis of Qualitative Choice Behavior," in Frontiers in Econometrics, ed. by P. Zarembka, New York: Academic Press.

- (1981): "Econometric Models of Probabilistic Choice," in Structural Analysis of Discrete Data with Econometric Applications, ed. by C. F. Manski, Cambridge, MA: MIT Press.

Post, T., M. J. van den Assem, G. Baltussen, and R. H. Thaler (2008): "Deal or No Deal? Decision Making under Risk in a Large-Payoff Game Show," American Economic Review, 98, 38-71.

Prelec, D. (1998): "The Probability Weighting Function," Econometrica, 66, 497-527.

- (2000): "Compound Invariant Weighting Functions in Prospect Theory," in Choices, Values, and Frames, ed. by D. Kahneman and A. Tversky, Cambridge: Cambridge University Press.

Quiggin, J. (1982): "A Theory of Anticipated Utility," Journal of Economic Behavior and Organization, 3, 323-343.

Rabin, M. (1998): "Psychology and Economics," Journal of Economic Literature, 36, 11-46. 
- (2000): "Risk Aversion and Expected-Utility Theory: A Calibration Theorem," Econometrica, 68, 1281-1292.

Rabin, M. And R. H. Thaler (2001): “Anomalies: Risk Aversion," Journal of Economic Perspectives, 15, 219-232.

Read, D., G. Loewenstein, And M. Rabin (1999): "Choice Bracketing," Journal of Risk and Uncertainty, 19, 171-197.

SCHMEIDlER, D. (1989): "Subjective Probability and Expected Utility Without Additivity," Econometrica, 57, 571-587.

SnowberG, E. And J. Wolfers (Forthcoming): "Explaining the Favorite-Longshot Bias: Is It Risk-Love or Misperceptions?" Journal of Political Economy.

Sydnor, J. (Forthcoming): "Over(Insuring) Modest Risks," American Economic Journal: Applied Economics.

Tanaka, T., C. F. Camerer, and Q. Nguyen (2010): "Risk and Time Preferences: Linking Experimental and Household Survey Data from Vietnam," American Economic Review, 100, 557-571.

Tversky, A. And D. Kahneman (1992): "Advances in Prospect Theory: Cumulative Representation of Uncertainty," Journal of Risk and Uncertainty, 5, 297-323.

Vuong, Q. H. (1989): "Likelihood Ratio Tests for Model Selection and Non-Nested Hypotheses," Econometrica, 57, 307-333. 


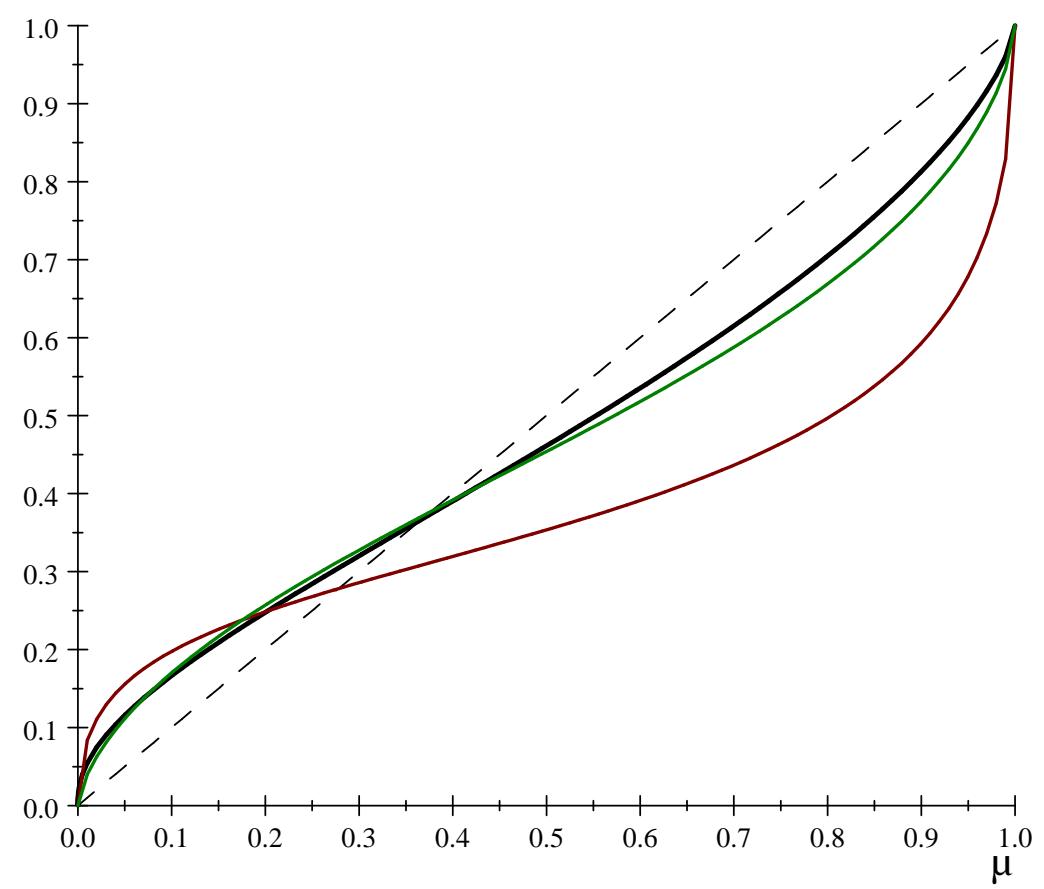

Figure 1: Probability Weighting Functions

Notes - The black curve is the Prelec (1998) function with $\alpha=0.7$. The red and green curves are the Tversky and Kahneman (1992) function with $\delta=0.5$ and $\delta=0.69$, respectively. The dashed line is the 45 degree line. 
Table 1: Descriptive Statistics

\section{Core Sample (4170 Households)}

\begin{tabular}{lcccc}
\hline \hline Variable & Mean & Std Dev & 1st Pctl & 99th Pctl \\
\hline Driver 1 age (years) & 54.5 & 15.4 & 26 & 84 \\
Driver 1 female & 0.37 & & & \\
Driver 1 single & 0.24 & & & \\
Driver 1 married & 0.51 & & 530 & 987 \\
Driver 1 credit score & 766 & 113 & & \\
Driver 2 indicator & 0.42 & & 10 & 619 \\
Home value (thousands of dollars) & 191 & 125 & & \\
\hline \hline
\end{tabular}

Note: Omitted category for driver 1 marital status is divorced or separated. 
Table 2: Summary of Deductible Choices

\begin{tabular}{lccc}
\multicolumn{4}{c}{ Core Sample (4170 Households) } \\
\hline \hline Deductible & Collision & Comp & Home \\
\hline$\$ 50$ & & 5.2 & \\
$\$ 100$ & 1.0 & 4.1 & 0.9 \\
$\$ 200$ & 13.4 & 33.5 & \\
$\$ 250$ & 11.2 & 10.6 & 29.7 \\
$\$ 500$ & 67.7 & 43.0 & 51.9 \\
$\$ 1000$ & 6.7 & 3.6 & 15.9 \\
$\$ 2500$ & & & 1.2 \\
$\$ 5000$ & & & 0.4 \\
\hline \hline
\end{tabular}

Note: Values are percent of households. 
Table 3: Summary of Premium Menus

Core Sample (4170 Households)

\begin{tabular}{|c|c|c|c|c|}
\hline Coverage & Mean & Std Dev & 1st Pctl & 99th Pctl \\
\hline Auto collision premium for $\$ 500$ deductible & 180 & 100 & 50 & 555 \\
\hline Auto comprehensive premium for $\$ 500$ deductible & 115 & 81 & 26 & 403 \\
\hline Home all perils premium for $\$ 500$ deductible & 679 & 519 & 216 & 2511 \\
\hline \multicolumn{5}{|l|}{ Cost of decreasing deductible from $\$ 500$ to $\$ 250:$} \\
\hline Auto collision & 54 & 31 & 14 & 169 \\
\hline Auto comprehensive & 30 & 22 & 6 & 107 \\
\hline Home all perils & 56 & 43 & 11 & 220 \\
\hline \multicolumn{5}{|l|}{ Savings from increasing deductible from $\$ 500$ to $\$ 1000$ : } \\
\hline Auto collision & 41 & 23 & 11 & 127 \\
\hline Auto comprehensive & 23 & 16 & 5 & 80 \\
\hline Home all perils & 74 & 58 & 15 & 294 \\
\hline
\end{tabular}

Note: Annual amounts in dollars. 
Table 4: Predicted Claim Rates (Annual)

Core Sample (4170 Households)

\begin{tabular}{lccc}
\hline \hline & Collision & Comp & Home \\
\hline Mean & 0.072 & 0.021 & 0.089 \\
Standard deviation & 0.026 & 0.011 & 0.053 \\
\hline 1st percentile & 0.026 & 0.004 & 0.025 \\
5th percentile & 0.035 & 0.007 & 0.034 \\
25th percentile & 0.053 & 0.013 & 0.054 \\
Median & 0.069 & 0.019 & 0.079 \\
75th percentile & 0.087 & 0.027 & 0.110 \\
95th percentile & 0.120 & 0.042 & 0.177 \\
99th percentile & 0.150 & 0.056 & 0.265 \\
\hline \hline Correlations & Collision & Comp & Home \\
\hline Collision & 1 & & \\
Comp & 0.13 & 1 & 1 \\
\hline Home & 0.27 & 0.19 & 0.24 \\
\hline Premium for coverage with $\$ 500$ deductible & 0.35 & 0.15 & \\
\hline \hline
\end{tabular}


Table 5: Benchmark Estimates (Model 2) Core Sample (4170 Households)

\begin{tabular}{|c|c|c|c|c|c|c|}
\hline & \multicolumn{2}{|c|}{$r$} & \multicolumn{2}{|c|}{$\Lambda$} & \multicolumn{2}{|c|}{$\alpha$} \\
\hline & Coef & Std Err & Coef & Std Err & Coef & Std Err \\
\hline Constant & $-16.06^{* *}$ & 0.95 & $-12.19 *$ & 6.70 & $-0.40^{* *}$ & 0.01 \\
\hline Driver 1 age & $-0.60 * *$ & 0.26 & $2.91^{* *}$ & 1.45 & $-0.04 * *$ & 0.01 \\
\hline Driver 1 age squared & $0.92^{* *}$ & 0.22 & -1.89 & 7.33 & 0.01 & 0.00 \\
\hline Driver 1 female & -0.18 & 0.20 & -0.44 & 1.99 & $-0.02 * *$ & 0.01 \\
\hline Driver 1 single & 0.06 & 0.27 & 0.83 & 1.32 & 0.00 & 0.01 \\
\hline Driver 1 married & $-4.32 * *$ & 0.75 & 0.48 & 1.15 & 0.00 & 0.01 \\
\hline Driver 1 credit score & 0.01 & 0.21 & 0.14 & 2.87 & $-0.06^{* *}$ & 0.01 \\
\hline \multirow[t]{2}{*}{ Driver 2 indicator } & -0.14 & 1.34 & -1.83 & 2.11 & $0.03 *$ & 0.01 \\
\hline & & & Coef & Std Err & & \\
\hline$\sigma$ & & & $2.93^{* *}$ & 0.05 & & \\
\hline Parameter mean & \multicolumn{2}{|c|}{0.0000299} & \multicolumn{2}{|c|}{0.0000} & \multicolumn{2}{|c|}{0.683} \\
\hline Parameter median & \multicolumn{2}{|c|}{0.0000001} & \multicolumn{2}{|c|}{0.0000} & \multicolumn{2}{|c|}{0.678} \\
\hline
\end{tabular}

Note: Each variable $z$ is normalized as $(z-\operatorname{mean}(z)) / \operatorname{stdev}(z)$.

** Significant at 5 percent level.

* Significant at 10 percent level. 
Table 6: Economic Significance of Benchmark Estimates

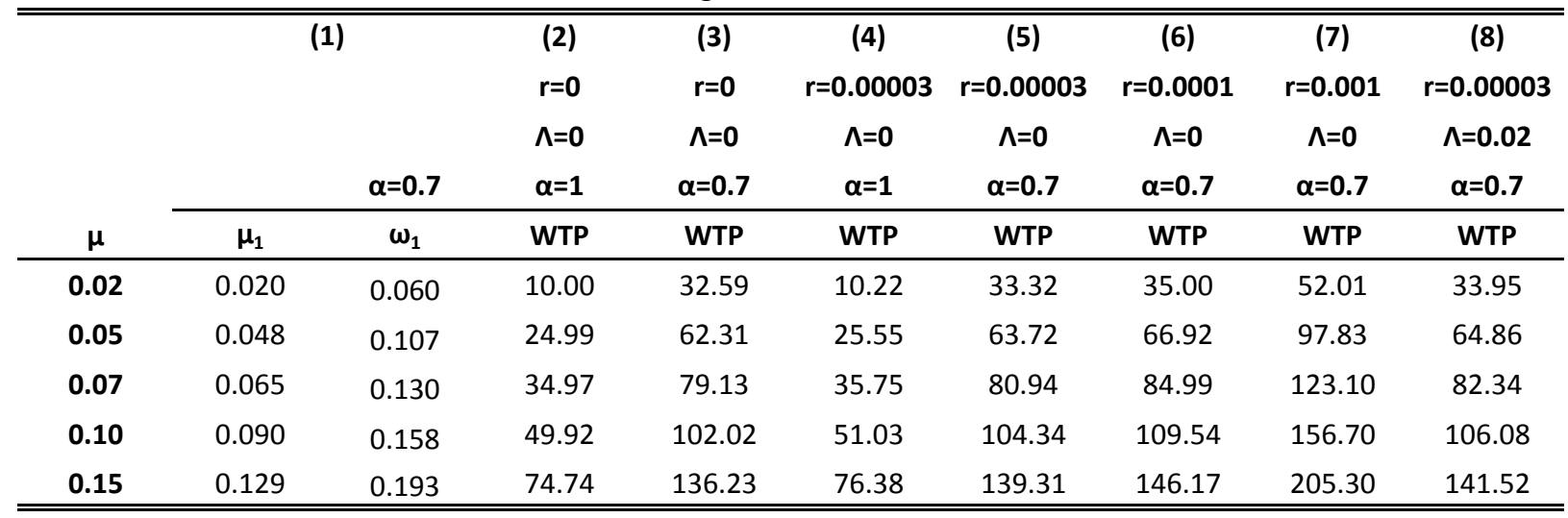

Note: WTP denotes--for a household with claim rate $\mu$, the utility function in equation (5), and the specified preference parameters--the household's maximum willingness to pay, in terms of excess premium above $\$ 200$, to decrease its deductible from $\$ 1000$ to $\$ 500$. 
Table 7: Mean Choice Probabilities

Core Sample (4170 Households)

\begin{tabular}{llccc}
\hline \hline & & Collision & Comp & Home \\
\hline$(1)$ & Random choice & 0.200 & 0.167 & 0.167 \\
$(2)$ & Full model - all households & 0.333 & 0.234 & 0.377 \\
$(3)$ & Full model - policies with $\$ 50$ or $\$ 100$ deductible & 0.194 & 0.139 & 0.089 \\
$(4)$ & Full model - policies with $\$ 200$ or $\$ 250$ deductible & 0.235 & 0.192 & 0.440 \\
$(5)$ & Full model - policies with $\$ 500$ deductible & 0.377 & 0.279 & 0.337 \\
$(6)$ & Full model - policies with $\$ 1000$ deductible & 0.269 & 0.439 & 0.427 \\
$(7)$ & Full model - policies with $\$ 2500$ or $\$ 5000$ deductible & & & 0.125 \\
$(8)$ & Restricted model $(\mathrm{r}=\Lambda=0)$ - all households & 0.332 & 0.234 & 0.376 \\
$(9)$ & Restricted model $(\Lambda=0, \alpha=1)$ - all households & 0.295 & 0.205 & 0.331 \\
\hline \hline
\end{tabular}


Table 8: Accounting for Wealth (Models 3-5)

Core Sample (4170 Households)

\begin{tabular}{lccc}
\hline \hline & $\mathbf{r}$ & $\Lambda$ & $\alpha$ \\
\hline Model 2: & 0.0000299 & 0.0000 & 0.683 \\
Parameter mean & 0.0000001 & 0.0000 & 0.678 \\
Parameter median & & & \\
\hline Model 3: & 0.0003803 & 0.0000 & 0.730 \\
Parameter mean & 0.0002531 & 0.0000 & 0.723 \\
Parameter median & & & 0.687 \\
\hline Model 4: & 0.0000690 & 0.0000 & 0.678 \\
Parameter mean & 0.0000003 & 0.0000 & \\
Parameter median & & & 0.684 \\
\hline Model 5: & 0.0000619 & 0.0001 & 0.675 \\
Parameter mean & 0.0000002 & 0.0000 & \\
Parameter median &
\end{tabular}

Table 9: Accounting for Unobserved Heterogeneity

Core Sample (4170 Households)

\begin{tabular}{lccc}
\hline \hline & $\boldsymbol{r}$ & $\Lambda$ & $\boldsymbol{\alpha}$ \\
\hline Model 2u: & & & \\
Parameter mean & 0.0010460 & 0.0001 & 0.817 \\
Parameter median & 0.0005689 & 0.0000 & 0.806 \\
\hline Model 5u: & & & \\
Parameter mean & 0.0007313 & 0.0000 & 0.785 \\
Parameter median & 0.0002334 & 0.0000 & 0.767 \\
\hline \hline
\end{tabular}




\section{Appendix (Not for Publication) to}

\section{The Nature of Risk Preferences: Evidence from Insurance Choices}

Levon Barseghyan

Cornell University

Ted O'Donoghue

Cornell University
Francesca Molinari

Cornell University

Joshua C. Teitelbaum

Georgetown University

July 21, 2010 
Table A.1: Summary of Premium Menus - Auto Collision

Core Sample (4170 Households)

\begin{tabular}{lcccccc}
\hline \hline & \multicolumn{5}{c}{ Deductible Choice } \\
\cline { 2 - 7 } & $\mathbf{\$ 1 0 0}$ & $\mathbf{\$ 2 0 0}$ & $\mathbf{\$ 2 5 0}$ & $\mathbf{\$ 5 0 0}$ & $\mathbf{\$ 1 0 0 0}$ & All \\
\hline Mean annual premium for coverage with $\$ 500$ deductible & 110 & 129 & 146 & 189 & 255 & 180 \\
Standard deviation & 54 & 54 & 66 & 96 & 168 & 100 \\
\hline Mean cost of decreasing deductible from $\$ 500$ to $\$ 250$ & 33 & 38 & 44 & 57 & 77 & 54 \\
Standard deviation & 17 & 17 & 20 & 29 & 52 & 31 \\
\hline Mean savings from increasing deductible from $\$ 500$ to $\$ 1000$ & 24 & 29 & 33 & 43 & 58 & 41 \\
Standard deviation & 12 & 12 & 15 & 22 & 39 & 23 \\
\hline Number of households & 42 & 559 & 467 & 2822 & 280 & 4170 \\
\hline \hline
\end{tabular}

Note: All values in dollars, except number of households.

Table A.2: Summary of Premium Menus - Auto Comprehensive

Core Sample (4170 Households)

\begin{tabular}{lcccccc}
\hline \hline & \multicolumn{5}{c}{ Deductible Choice } \\
\cline { 2 - 7 } & $\mathbf{\$ 5 0}$ & $\mathbf{\$ 1 0 0}$ & $\mathbf{\$ 2 0 0}$ & $\mathbf{\$ 2 5 0}$ & $\mathbf{\$ 5 0 0}$ & $\mathbf{\$ 1 0 0 0}$ \\
\hline Mean annual premium for coverage with $\$ 500$ deductible & 61 & 70 & 92 & 98 & 136 & 258 \\
Standard deviation & 27 & 33 & 43 & 41 & 71 & 247 \\
\hline Mean cost of decreasing deductible from $\$ 500$ to $\$ 250$ & 16 & 18 & 24 & 26 & 36 & 68 \\
Standard deviation & 7 & 9 & 11 & 11 & 19 & 66 \\
\hline Mean savings from increasing deductible from $\$ 500$ to $\$ 1000$ & 12 & 14 & 18 & 19 & 27 & 51 \\
Standard deviation & 5 & 7 & 9 & 8 & 14 & 49 \\
\hline Number of households & 216 & 171 & 1397 & 440 & 1795 & 151 \\
\hline \hline
\end{tabular}

Note: All values in dollars, except number of households.

Table A.3: Summary of Premium Menus - Home

Core Sample (4170 Households)

\begin{tabular}{|c|c|c|c|c|c|c|}
\hline & \multirow[b]{2}{*}{$\$ 100$} & \multicolumn{5}{|c|}{ Deductible Choice } \\
\hline & & $\$ 250$ & $\$ 500$ & $\$ 1000$ & $\$ 2500$ & $\$ 5000$ \\
\hline Mean annual premium for coverage with $\$ 500$ deductible & 366 & 520 & 631 & 972 & 2218 & 3366 \\
\hline Standard deviation & 113 & 218 & 308 & 593 & 2289 & 1808 \\
\hline Mean cost of decreasing deductible from $\$ 500$ to $\$ 250$ & 31 & 42 & 52 & 80 & 183 & 275 \\
\hline Standard deviation & 6 & 18 & 26 & 48 & 201 & 140 \\
\hline Mean savings from increasing deductible from $\$ 500$ to $\$ 1000$ & 41 & 57 & 69 & 107 & 244 & 368 \\
\hline Standard deviation & 8 & 23 & 34 & 64 & 268 & 188 \\
\hline Number of households & 36 & 1239 & 2166 & 664 & 50 & 15 \\
\hline
\end{tabular}

Note: All values in dollars, except number of households. 
Table A.4: Claim Rate Regressions - Auto

Poisson Panel Regression Model with Random Effects

Full Data Set $(1,348,020$ Household-Year Records )

\begin{tabular}{|c|c|c|c|c|}
\hline & \multicolumn{2}{|c|}{ Collision } & \multicolumn{2}{|c|}{ Comprehensive } \\
\hline & Coef & Std Err & Coef & Std Err \\
\hline Constant & $-6.7646 * *$ & 0.0616 & $-7.9277^{* *}$ & 0.1057 \\
\hline Driver 2 Indicator & -0.0485 & 0.0593 & $-0.3542 * *$ & 0.1022 \\
\hline Driver $3+$ Indicator & $0.3215^{* *}$ & 0.0733 & -0.1261 & 0.1201 \\
\hline Vehicle 2 Indicator & $0.5991^{* *}$ & 0.0466 & $0.6502 * *$ & 0.0782 \\
\hline Vehicle $3+$ Indicator & $0.7312^{* *}$ & 0.0596 & $0.8766^{* *}$ & 0.0937 \\
\hline Young Driver & -0.0058 & 0.0296 & $0.0895^{* *}$ & 0.0453 \\
\hline Driver 1 Age & $-0.0210 * *$ & 0.0015 & $0.0113 * *$ & 0.0029 \\
\hline Driver 1 Age Squared & $0.0002 * *$ & 0.0000 & $-0.0002 * *$ & 0.0000 \\
\hline Driver 1 Female & $0.1040^{* *}$ & 0.0093 & $-0.0672 * *$ & 0.0168 \\
\hline Driver 1 Married & $0.0630 * *$ & 0.0111 & $0.0640^{* *}$ & 0.0201 \\
\hline Driver 1 Divorced & 0.0186 & 0.0141 & $0.0914 * *$ & 0.0247 \\
\hline Driver 1 Separated & 0.0392 & 0.0256 & 0.0791 & 0.0428 \\
\hline Driver 1 Single & . & . & . & . \\
\hline Driver 1 Widowed & 0.0031 & 0.0160 & -0.0170 & 0.0335 \\
\hline Vehicle 1 Age & $-0.0354 * *$ & 0.0019 & $-0.0286 * *$ & 0.0030 \\
\hline Vehicle 1 Age Squared & $-0.0006 * *$ & 0.0001 & 0.0000 & 0.0002 \\
\hline Vehicle 1 Business & . & . & . & . \\
\hline Vehicle 1 Farm & $-0.2575^{* *}$ & 0.0872 & 0.0206 & 0.1194 \\
\hline Vehicle 1 Pleasure & $-0.1094^{* *}$ & 0.0306 & $-0.1118^{* *}$ & 0.0526 \\
\hline Vehicle 1 Work & $-0.0831 * *$ & 0.0304 & -0.0620 & 0.0523 \\
\hline Vehicle 1 Passive Restraint & $-0.1087^{* *}$ & 0.0239 & $-0.0858 * *$ & 0.0352 \\
\hline Vehicle 1 Anti-Theft & $0.0754^{* *}$ & 0.0078 & $0.0735^{* *}$ & 0.0136 \\
\hline Vehicle 1 Anti-Lock & $0.0581 * *$ & 0.0080 & $0.0729 * *$ & 0.0139 \\
\hline Driver 2 Age & $0.0115^{* *}$ & 0.0024 & $0.0181 * *$ & 0.0042 \\
\hline Driver 2 Age Squared & $-0.0001^{* *}$ & 0.0000 & $-0.0001 * *$ & 0.0000 \\
\hline Driver 2 Female & $0.1204^{* *}$ & 0.0151 & -0.0376 & 0.0257 \\
\hline Driver 2 Married & $-0.0835 * *$ & 0.0191 & -0.0408 & 0.0326 \\
\hline Driver 2 Divorced & -0.1579 & 0.1027 & -0.1347 & 0.1636 \\
\hline Driver 2 Separated & 0.0254 & 0.2130 & 0.1796 & 0.3226 \\
\hline Driver 2 Single & . & . & . & . \\
\hline Driver 2 Widowed & -0.0802 & 0.1383 & $-1.1835^{* *}$ & 0.3864 \\
\hline Vehicle 2 Age & $-0.0332 * *$ & 0.0016 & $-0.0229 * *$ & 0.0027 \\
\hline Vehicle 2 Age Squared & $0.0004^{* *}$ & 0.0001 & $0.0002 * *$ & 0.0001 \\
\hline Vehicle 2 Business & . & . & . & . \\
\hline Vehicle 2 Farm & -0.1703 & 0.1056 & -0.1345 & 0.1500 \\
\hline Vehicle 2 Pleasure & $-0.1805^{* *}$ & 0.0380 & -0.0563 & 0.0663 \\
\hline Vehicle 2 Work & $-0.1670 * *$ & 0.0381 & 0.0119 & 0.0664 \\
\hline Vehicle 2 Passive Restraint & $-0.0428 * *$ & 0.0201 & $-0.0875 * *$ & 0.0294 \\
\hline Vehicle 2 Anti-Theft & $0.0547^{* *}$ & 0.0103 & $0.0385^{* *}$ & 0.0171 \\
\hline Vehicle 2 Anti-Lock & $0.0317^{* *}$ & 0.0105 & 0.0199 & 0.0170 \\
\hline Driver 1 Credit Score & $-0.0017^{* *}$ & 0.0000 & $-0.0013 * *$ & 0.0001 \\
\hline Driver 1 Previous Accident & $0.0913^{* *}$ & 0.0156 & $0.0756^{* *}$ & 0.0277 \\
\hline Driver 1 Previous Convictions & 0.1476 & 0.0888 & 0.0648 & 0.1670 \\
\hline Driver 1 Previous Reinstated & 0.0170 & 0.0558 & 0.0003 & 0.0996 \\
\hline Driver 1 Previous Revocation & -0.0218 & 0.1456 & 0.3156 & 0.1967 \\
\hline Driver 1 Previous Suspension & 0.0463 & 0.0564 & 0.0125 & 0.1026 \\
\hline Driver 1 Previous Violation & $0.0827^{* *}$ & 0.0093 & $0.0577^{* *}$ & 0.0161 \\
\hline Year Dummies & \multicolumn{2}{|c|}{ Yes } & \multicolumn{2}{|c|}{ Yes } \\
\hline Territory Codes & \multicolumn{2}{|c|}{ Yes } & \multicolumn{2}{|c|}{ Yes } \\
\hline Variance $(\phi)$ & $0.2242 * *$ & 0.0065 & 0.5661 & 0.0198 \\
\hline Loglikelihood & \multicolumn{2}{|c|}{$-399,318$} & \multicolumn{2}{|c|}{$-169,817$} \\
\hline
\end{tabular}

A -2 
Table A.5: Claim Rate Regression - Home Poisson Panel Regression Model with Random Effects Full Data Set $(1,265,229$ Household-Year Records )

\begin{tabular}{|c|c|c|}
\hline & Coef & Std Err \\
\hline Constant & $-7.3642 * *$ & 0.0978 \\
\hline Dwelling Value & $0.0000 * *$ & 0.0000 \\
\hline Home Age & $0.0016 * *$ & 0.0006 \\
\hline Home Age Squared & $0.0000 * *$ & 0.0000 \\
\hline Number of Families & -0.0021 & 0.0023 \\
\hline Distance to Hydrant & 0.0000 & 0.0000 \\
\hline Alarm Discount & $0.2463 * *$ & 0.0195 \\
\hline Protection Devices & $-0.1852 * *$ & 0.0239 \\
\hline Farm/Business & $0.1044 * *$ & 0.0242 \\
\hline Primary Home & $0.4832 * *$ & 0.0819 \\
\hline Owner Occupied & $0.2674 * *$ & 0.0419 \\
\hline Construction: Fire Resist & 0.1525 & 0.1342 \\
\hline Construction: Masonry & $0.0751 * *$ & 0.0172 \\
\hline Construction: Masonry/Veneer & $0.0755 * *$ & 0.0252 \\
\hline Construction: Frame & . & . \\
\hline Credit Score & $-0.0026 * *$ & 0.0000 \\
\hline Year Dummies & \multicolumn{2}{|c|}{ Yes } \\
\hline Protection Classes & \multicolumn{2}{|c|}{ Yes } \\
\hline Territory Codes & \multicolumn{2}{|c|}{ Yes } \\
\hline Variance $(\phi)$ & $0.4514^{* *}$ & 0.0086 \\
\hline Loglikelihood & \multicolumn{2}{|c|}{$-347,278$} \\
\hline
\end{tabular}

** Significant at 5 percent level. 
Table A.6: Model 3 Estimates

Core Sample (4170 Households)

\begin{tabular}{|c|c|c|c|c|c|c|}
\hline & \multicolumn{2}{|c|}{$\mathbf{r}$} & \multicolumn{2}{|c|}{$\Lambda$} & \multicolumn{2}{|c|}{$\alpha$} \\
\hline & Coef & Std Err & Coef & Std Err & Coef & Std Err \\
\hline Constant & $-8.61 * *$ & 0.21 & $-17.00 * *$ & 4.24 & $-0.34 * *$ & 0.01 \\
\hline Driver 1 age & $-0.64^{* *}$ & 0.11 & 0.77 & 3.44 & $-0.07^{* *}$ & 0.01 \\
\hline Driver 1 age squared & 0.02 & 0.07 & -0.26 & 2.45 & 0.01 & 0.00 \\
\hline Driver 1 female & -0.11 & 0.07 & 0.79 & 1.03 & $-0.02 * *$ & 0.01 \\
\hline Driver 1 single & 0.14 & 0.09 & -0.81 & 1.59 & 0.01 & 0.01 \\
\hline Driver 1 married & -0.09 & 0.15 & -0.50 & 1.07 & 0.00 & 0.01 \\
\hline Driver 1 credit score & 0.03 & 0.07 & -0.98 & 1.26 & $-0.06 * *$ & 0.01 \\
\hline Driver 2 indicator & 0.41 & 0.28 & $5.71^{* *}$ & 1.15 & 0.03 & 0.02 \\
\hline \multirow[t]{2}{*}{ Home value } & $-1.20^{* *}$ & 0.10 & 0.12 & 0.23 & 0.00 & 0.00 \\
\hline & & & Coef & Std Err & & \\
\hline$\sigma$ & & & $2.45^{* *}$ & 0.07 & & \\
\hline Parameter mean & \multicolumn{2}{|c|}{0.0003803} & \multicolumn{2}{|c|}{0.0000} & \multicolumn{2}{|c|}{0.730} \\
\hline Parameter median & \multicolumn{2}{|c|}{0.0002531} & \multicolumn{2}{|c|}{0.0000} & \multicolumn{2}{|c|}{0.723} \\
\hline
\end{tabular}

Note: Each variable $z$ is normalized as $(z-\operatorname{mean}(z)) / \operatorname{stdev}(z)$.

** Significant at 5 percent level.

Table A.7: Model 4 Estimates

Core Sample (4170 Households)

\begin{tabular}{|c|c|c|c|c|c|c|}
\hline & \multicolumn{2}{|c|}{$\mathbf{r}$} & \multicolumn{2}{|c|}{$\Lambda$} & \multicolumn{2}{|c|}{$\alpha$} \\
\hline & Coef & Std Err & Coef & Std Err & Coef & Std Err \\
\hline Constant & -3.48 & 2.60 & $-14.97 * *$ & 2.24 & $-0.41 * *$ & 0.01 \\
\hline Driver 1 age & $-6.76 * *$ & 3.21 & -0.79 & 6.25 & $-0.05 * *$ & 0.01 \\
\hline Driver 1 age squared & -1.28 & 1.02 & -1.12 & 5.79 & $0.01 * *$ & 0.00 \\
\hline Driver 1 female & $-0.37 * *$ & 0.16 & -1.24 & 1.80 & $-0.02 * *$ & 0.01 \\
\hline Driver 1 single & -0.12 & 0.21 & -2.91 & 6.25 & 0.00 & 0.01 \\
\hline Driver 1 married & -0.44 & 0.32 & 2.60 & 4.99 & 0.00 & 0.01 \\
\hline Driver 1 credit score & 0.10 & 0.17 & 0.89 & 3.67 & $-0.06 * *$ & 0.00 \\
\hline \multirow[t]{2}{*}{ Driver 2 present } & 0.43 & 0.53 & -0.54 & 3.54 & $0.03 *$ & 0.01 \\
\hline & & & Coef & Std Err & & \\
\hline$\sigma$ & & & $2.89 * *$ & 0.05 & & \\
\hline Parameter mean & \multicolumn{2}{|c|}{0.000069} & \multicolumn{2}{|c|}{0.0000} & \multicolumn{2}{|c|}{0.687} \\
\hline Parameter median & \multicolumn{2}{|c|}{0.0000003} & \multicolumn{2}{|c|}{0.0000} & \multicolumn{2}{|c|}{0.678} \\
\hline
\end{tabular}

Note: Each variable $z$ is normalized as $(z-\operatorname{mean}(z)) / \operatorname{stdev}(z)$.

** Significant at 5 percent level.

* Significant at 10 percent level. 
Table A.8: Model 5 Estimates

Core Sample (4170 Households)

\begin{tabular}{|c|c|c|c|c|c|c|}
\hline & \multicolumn{2}{|c|}{$r$} & \multicolumn{2}{|c|}{$\Lambda$} & \multicolumn{2}{|c|}{$\alpha$} \\
\hline & Coef & Std Err & Coef & Std Err & Coef & Std Err \\
\hline Constant & $-3.93 * *$ & 0.62 & $-19.65 * *$ & 3.01 & $-0.41 * *$ & 0.01 \\
\hline Driver 1 age & $-7.09 * *$ & 0.58 & -0.89 & 10.67 & $-0.05 * *$ & 0.01 \\
\hline Driver 1 age squared & $-1.34^{* *}$ & 0.28 & -9.95 & 7.02 & $0.01 * *$ & 0.00 \\
\hline Driver 1 female & $-0.40 * *$ & 0.18 & 1.09 & 2.04 & $-0.02 * *$ & 0.01 \\
\hline Driver 1 single & -0.11 & 0.24 & -0.47 & 1.09 & 0.00 & 0.01 \\
\hline Driver 1 married & -0.42 & 0.34 & -3.96 & 4.78 & 0.00 & 0.01 \\
\hline Driver 1 credit score & 0.07 & 0.17 & 0.30 & 1.44 & $-0.06 * *$ & 0.01 \\
\hline Driver 2 indicator & 0.35 & 0.52 & 0.15 & 1.72 & $0.02^{* *}$ & 0.00 \\
\hline \multirow[t]{2}{*}{ Home value } & 0.03 & 0.14 & $1.34^{* *}$ & 0.35 & 0.02 & 0.02 \\
\hline & & & Coef & Std Err & & \\
\hline$\sigma$ & & & $2.89^{* *}$ & 0.05 & & \\
\hline Parameter mean & \multicolumn{2}{|c|}{0.0000619} & \multicolumn{2}{|c|}{0.0001} & \multicolumn{2}{|c|}{0.684} \\
\hline Parameter median & \multicolumn{2}{|c|}{0.0000002} & \multicolumn{2}{|c|}{0.0000} & \multicolumn{2}{|c|}{0.675} \\
\hline
\end{tabular}

Note: Each variable $z$ is normalized as $(z-\operatorname{mean}(z)) / \operatorname{stdev}(z)$.

** Significant at 5 percent level. 
Table A.9: Model 2u Estimates

Core Sample (4170 Households)

\begin{tabular}{|c|c|c|c|c|c|c|}
\hline & \multicolumn{2}{|c|}{$\mathbf{r}$} & \multicolumn{2}{|c|}{$\Lambda$} & \multicolumn{2}{|c|}{$\alpha$} \\
\hline & Coef & Std Err & Coef & Std Err & Coef & Std Err \\
\hline Constant & $-7.37^{* *}$ & 0.17 & $-17.00 * *$ & 2.04 & $-0.23 * *$ & 0.01 \\
\hline Driver 1 age & $-0.98 * *$ & 0.13 & -4.42 & 4.49 & $-0.10 * *$ & 0.01 \\
\hline Driver 1 age squared & 0.11 & 0.08 & $-9.87 * *$ & 1.56 & $0.01 *$ & 0.01 \\
\hline Driver 1 female & $0.16 *$ & 0.10 & $-5.40 * *$ & 2.21 & 0.01 & 0.01 \\
\hline Driver 1 single & -0.02 & 0.11 & 0.31 & 1.56 & 0.00 & 0.01 \\
\hline Driver 1 married & 0.19 & 0.15 & 4.75 & 2.97 & 0.01 & 0.01 \\
\hline Driver 1 credit score & -0.09 & 0.09 & -0.85 & 3.24 & $-0.07 *$ & 0.01 \\
\hline \multirow[t]{2}{*}{ Driver 2 indicator } & -0.32 & 0.22 & 1.07 & 1.67 & 0.01 & 0.02 \\
\hline & & & Coef & Std Err & & \\
\hline$\sigma$ & & & $3.14^{* *}$ & 0.08 & & \\
\hline Parameter mean & \multicolumn{2}{|c|}{0.001046} & \multicolumn{2}{|c|}{0.0001} & \multicolumn{2}{|c|}{0.817} \\
\hline Parameter median & \multicolumn{2}{|c|}{0.0005689} & \multicolumn{2}{|c|}{0.0000} & \multicolumn{2}{|c|}{0.086} \\
\hline
\end{tabular}

Note: Each variable $z$ is normalized as $(z-\operatorname{mean}(z)) / \operatorname{stdev}(z)$.

** Significant at 5 percent level.

* Significant at 10 percent level.

Table A.10: Model 5u Estimates

Core Sample (4170 Households)

\begin{tabular}{|c|c|c|c|c|c|c|}
\hline & \multicolumn{2}{|c|}{$\mathbf{r}$} & \multicolumn{2}{|c|}{$\Lambda$} & \multicolumn{2}{|c|}{$\alpha$} \\
\hline & Coef & Std Err & Coef & Std Err & Coef & Std Err \\
\hline Constant & $3.87^{* *}$ & 0.25 & $-22.52 * *$ & 3.12 & $-0.27^{* *}$ & 0.01 \\
\hline Driver 1 age & $-1.55 * *$ & 0.18 & $8.70 * *$ & 1.84 & $-0.10 * *$ & 0.01 \\
\hline Driver 1 age squared & 0.00 & 0.11 & $-12.80 * *$ & 4.44 & $0.02 * *$ & 0.01 \\
\hline Driver 1 female & $-0.22 * *$ & 0.10 & 0.24 & 2.12 & $-0.02 * *$ & 0.01 \\
\hline Driver 1 single & -0.09 & 0.11 & -0.90 & 2.85 & -0.01 & 0.01 \\
\hline Driver 1 married & 0.20 & 0.16 & -2.91 & 3.12 & 0.00 & 0.01 \\
\hline Driver 1 credit score & 0.06 & 0.09 & 1.87 & 2.86 & $-0.06 * *$ & 0.01 \\
\hline Driver 2 indicator & $-0.64 * *$ & 0.30 & -1.15 & 1.34 & 0.00 & 0.02 \\
\hline \multirow[t]{2}{*}{ Home value } & -0.02 & 0.06 & $-1.99 * *$ & 0.74 & $-0.01 * *$ & 0.00 \\
\hline & & & Coef & Std Err & & \\
\hline$\sigma$ & & & $3.34^{* *}$ & 0.10 & & \\
\hline Parameter mean & \multicolumn{2}{|c|}{0.0007313} & \multicolumn{2}{|c|}{0.0000} & \multicolumn{2}{|c|}{0.785} \\
\hline Parameter median & \multicolumn{2}{|c|}{0.0002334} & \multicolumn{2}{|c|}{0.0000} & \multicolumn{2}{|c|}{0.767} \\
\hline
\end{tabular}

Note: Each variable $z$ is normalized as $(z-\operatorname{mean}(z)) / \operatorname{stdev}(z)$.

** Significant at 5 percent level. 
Table A.11: Model 2 with Cumulative Form of Rank Dependence Core Sample (4170 Households)

\begin{tabular}{|c|c|c|c|c|c|c|}
\hline & \multicolumn{2}{|c|}{$\mathbf{r}$} & \multicolumn{2}{|c|}{$\Lambda$} & \multicolumn{2}{|c|}{$\alpha$} \\
\hline & Coef & Std Err & Coef & Std Err & Coef & Std Err \\
\hline Constant & $-13.99 * *$ & 1.98 & $-11.67 * *$ & 4.14 & $-0.37 * *$ & 0.01 \\
\hline Driver 1 age & $-3.97 * *$ & 0.87 & 1.43 & 1.33 & $-0.04 * *$ & 0.00 \\
\hline Driver 1 age squared & $-0.76 * *$ & 0.38 & $-5.03 * *$ & 2.09 & 0.00 & 0.00 \\
\hline Driver 1 female & 0.22 & 0.19 & -0.08 & 1.06 & $-0.01 * *$ & 0.00 \\
\hline Driver 1 single & 0.01 & 0.17 & -1.33 & 1.05 & 0.00 & 0.01 \\
\hline Driver 1 married & -1.71 & 1.97 & 0.69 & 1.04 & -0.01 & 0.01 \\
\hline Driver 1 credit score & $0.49^{* *}$ & 0.22 & 1.61 & 1.81 & $-0.04 * *$ & 0.00 \\
\hline \multirow[t]{2}{*}{ Driver 2 indicator } & -5.05 & 4.69 & -2.07 & 1.24 & 0.02 & 0.01 \\
\hline & & & Coef & Std Err & & \\
\hline$\sigma$ & & & $3.25^{* *}$ & 0.06 & & \\
\hline Parameter mean & \multicolumn{2}{|c|}{0.0000298} & \multicolumn{2}{|c|}{0.0000} & \multicolumn{2}{|c|}{0.698} \\
\hline Parameter median & \multicolumn{2}{|c|}{0.0000000} & \multicolumn{2}{|c|}{0.0000} & \multicolumn{2}{|c|}{0.695} \\
\hline
\end{tabular}

Note: Each variable $z$ is normalized as $(z-\operatorname{mean}(z)) / \operatorname{stdev}(z)$.

** Significant at 5 percent level.

Table A.12: Model 5 with Cumulative Form of Rank Dependence Core Sample (4170 Households)

\begin{tabular}{|c|c|c|c|c|c|c|}
\hline & \multicolumn{2}{|c|}{$r$} & \multicolumn{2}{|c|}{$\Lambda$} & \multicolumn{2}{|c|}{$\alpha$} \\
\hline & Coef & Std Err & Coef & Std Err & Coef & Std Err \\
\hline Constant & $-8.06 *$ & 4.70 & $-12.45 * *$ & 1.32 & $-0.38 * *$ & 0.01 \\
\hline Driver 1 age & $-4.91 * *$ & 2.02 & 0.27 & 1.00 & $-0.04 * *$ & 0.00 \\
\hline Driver 1 age squared & -0.86 & 0.74 & -1.35 & 1.12 & 0.00 & 0.00 \\
\hline Driver 1 female & -0.12 & 0.27 & -0.43 & 1.03 & $-0.01 * *$ & 0.01 \\
\hline Driver 1 single & -0.12 & 0.23 & -0.29 & 1.01 & 0.00 & 0.01 \\
\hline Driver 1 married & $-6.45 * *$ & 3.19 & 0.40 & 3.71 & -0.01 & 0.01 \\
\hline Driver 1 credit score & 0.34 & 0.34 & 0.14 & 1.04 & $-0.04^{* *}$ & 0.00 \\
\hline Driver 2 indicator & $-7.67 * *$ & 2.34 & 0.38 & 1.01 & 0.02 & 0.01 \\
\hline \multirow[t]{2}{*}{ Home value } & $0.46^{* *}$ & 0.13 & -0.12 & 1.02 & $0.01 * *$ & 0.00 \\
\hline & & & Coef & Std Err & & \\
\hline$\sigma$ & & & $3.26^{* *}$ & 0.05 & & \\
\hline Parameter mean & \multicolumn{2}{|c|}{0.0000242} & \multicolumn{2}{|c|}{0.0000} & \multicolumn{2}{|c|}{0.695} \\
\hline Parameter median & \multicolumn{2}{|c|}{0.0000000} & \multicolumn{2}{|c|}{0.0000} & \multicolumn{2}{|c|}{0.693} \\
\hline
\end{tabular}

Note: Each variable $z$ is normalized as $(z-\operatorname{mean}(z)) / \operatorname{stdev}(z)$.

** Significant at 5 percent level.

* Significant at 10 percent level. 
Table A.13: Model 2 with Tversky and Kahneman (1992) Probability Weighting Function and Cumulative Form of Rank Dependence

\begin{tabular}{|c|c|c|c|c|c|c|}
\hline \multicolumn{7}{|c|}{ Core Sample (4170 Households) } \\
\hline & \multicolumn{2}{|c|}{$r$} & \multicolumn{2}{|c|}{$\Lambda$} & \multicolumn{2}{|c|}{$\delta$} \\
\hline & Coef & Std Err & Coef & Std Err & Coef & Std Err \\
\hline Constant & $-15.63 * *$ & 1.42 & $-21.00 * *$ & 4.13 & $-0.45 * *$ & 0.01 \\
\hline Driver 1 age & $-2.16^{* *}$ & 0.25 & $15.17^{* *}$ & 4.80 & $-0.03 * *$ & 0.01 \\
\hline Driver 1 age squared & -1.40 & 0.52 & $-5.13 * *$ & 1.85 & $-0.03 * *$ & 0.01 \\
\hline Driver 1 female & -0.80 & 0.52 & -0.21 & 0.42 & $-0.03 * *$ & 0.01 \\
\hline Driver 1 single & -0.27 & 0.30 & -0.83 & 0.97 & 0.00 & 0.01 \\
\hline Driver 1 married & $-3.08 * *$ & 1.19 & $-1.99 * *$ & 0.42 & -0.01 & 0.01 \\
\hline Driver 1 credit score & $2.57^{* *}$ & 0.61 & 0.17 & 0.19 & $-0.04 * *$ & 0.01 \\
\hline \multirow[t]{2}{*}{ Driver 2 indicator } & -0.93 & 2.35 & $10.01^{* *}$ & 3.91 & $-1.12 * *$ & 0.02 \\
\hline & & & Coef & Std Err & & \\
\hline$\sigma$ & & & $3.09^{* *}$ & 0.05 & & \\
\hline Parameter mean & \multicolumn{2}{|c|}{0.0000830} & \multicolumn{2}{|c|}{0.0212} & \multicolumn{2}{|c|}{0.438} \\
\hline Parameter median & \multicolumn{2}{|c|}{0.0000000} & \multicolumn{2}{|c|}{0.0000} & \multicolumn{2}{|c|}{0.556} \\
\hline
\end{tabular}

Note: Each variable $z$ is normalized as $(z-\operatorname{mean}(z)) / \operatorname{stdev}(z)$.

** Significant at 5 percent level.

Table A.14: Model 2 with Linear Probability Weighting Function Core Sample (4170 Households)

\begin{tabular}{|c|c|c|c|c|c|c|}
\hline & \multicolumn{2}{|c|}{$r$} & \multicolumn{2}{|c|}{$\Lambda$} & \multicolumn{2}{|c|}{$\alpha$} \\
\hline & Coef & Std Err & Coef & Std Err & Coef & Std Err \\
\hline Constant & $-12.03 * *$ & 0.51 & $-11.11 * *$ & 2.81 & $-0.31 * *$ & 0.01 \\
\hline Driver 1 age & $-0.56^{* *}$ & 0.16 & 3.90 & 4.19 & $-0.03 * *$ & 0.00 \\
\hline Driver 1 age squared & $0.97 * *$ & 0.09 & $-6.49 * *$ & 2.85 & $0.01 * *$ & 0.00 \\
\hline Driver 1 female & -0.16 & 0.17 & 1.66 & 1.60 & $-0.01 * *$ & 0.00 \\
\hline Driver 1 single & 0.00 & 0.23 & 0.32 & 6.30 & 0.00 & 0.00 \\
\hline Driver 1 married & $-0.47 * *$ & 0.42 & 0.80 & 3.70 & 0.00 & 0.01 \\
\hline Driver 1 credit score & $0.05 * *$ & 0.18 & 0.81 & 3.72 & $-0.04 * *$ & 0.00 \\
\hline \multirow[t]{2}{*}{ Driver 2 indicator } & $-6.67^{* *}$ & 1.10 & -2.20 & 2.80 & 0.01 & 0.01 \\
\hline & & & Coef & Std Err & & \\
\hline$\sigma$ & & & $2.91^{* *}$ & 0.05 & & \\
\hline Parameter mean & \multicolumn{2}{|c|}{0.0000352} & \multicolumn{2}{|c|}{0.0000} & \multicolumn{2}{|c|}{0.740} \\
\hline Parameter median & \multicolumn{2}{|c|}{0.0000075} & \multicolumn{2}{|c|}{0.0000} & \multicolumn{2}{|c|}{0.736} \\
\hline
\end{tabular}

Note: Each variable $z$ is normalized as $(z-\operatorname{mean}(z)) / \operatorname{stdev}(z)$.

** Significant at 5 percent level. 
Table A.15: Model 2 with Lattimore et al. (1992) Probability Weighting Function Core Sample (4170 Households)

\begin{tabular}{|c|c|c|c|c|c|c|c|c|c|}
\hline & \multicolumn{2}{|c|}{$r$} & \multicolumn{2}{|c|}{$\Lambda$} & \multicolumn{3}{|c|}{ a } & \multicolumn{2}{|l|}{$\delta$} \\
\hline & Coef & Std Err & Coef & Std Err & & Coef & Std Err & Coef & Std Err \\
\hline Constant & $-18.91 * *$ & 2.18 & $-12.73^{* *}$ & 1.00 & & $1.42 * *$ & 0.08 & $-1.39 * *$ & 0.07 \\
\hline Driver 1 age & $-1.87^{*}$ & 1.07 & 0.04 & 0.99 & & $-0.17^{* *}$ & 0.04 & $0.08^{*}$ & 0.04 \\
\hline Driver 1 age squared & -0.20 & 0.42 & -0.01 & 1.00 & & $0.11^{* *}$ & 0.03 & $-0.09 * *$ & 0.03 \\
\hline Driver 1 female & $0.26^{* *}$ & 0.10 & -0.03 & 1.00 & & 0.03 & 0.05 & -0.07 & 0.05 \\
\hline Driver 1 single & 0.16 & 0.10 & 0.02 & 1.00 & & 0.07 & 0.05 & -0.06 & 0.06 \\
\hline Driver 1 married & $-8.70 * *$ & 2.08 & -0.01 & 1.00 & & $-0.12 *$ & 0.07 & 0.08 & 0.07 \\
\hline Driver 1 credit score & 0.03 & 0.09 & -0.01 & 1.00 & & $-0.12 * *$ & 0.03 & $0.08^{* *}$ & 0.03 \\
\hline \multirow[t]{2}{*}{ Driver 2 indicator } & -0.40 & 1.03 & 0.01 & 1.00 & & 0.03 & 0.11 & 0.01 & 0.11 \\
\hline & \multicolumn{5}{|c|}{ Coef } & \multicolumn{2}{|l|}{ Std Err } & & \\
\hline$\sigma$ & & & & 3.55 & $* *$ & 0.06 & & & \\
\hline Parameter mean & \multicolumn{2}{|c|}{0.0000864} & \multicolumn{2}{|c|}{0.0000} & \multicolumn{3}{|c|}{4.996} & \multicolumn{2}{|c|}{0.235} \\
\hline Parameter median & \multicolumn{2}{|c|}{0.0000000} & \multicolumn{2}{|c|}{0.0000} & \multicolumn{3}{|c|}{4.954} & \multicolumn{2}{|c|}{0.230} \\
\hline
\end{tabular}

Note: Each variable $z$ is normalized as $(z-\operatorname{mean}(z)) / \operatorname{stdev}(z)$.

** Significant at 5 percent level.

* Significant at 10 percent level. 
Table A.16: Model 3 with CARA Utility

Core Sample (4170 Households)

\begin{tabular}{|c|c|c|c|c|c|c|}
\hline & \multicolumn{2}{|c|}{$\mathbf{r}$} & \multicolumn{2}{|c|}{$\Lambda$} & \multicolumn{2}{|c|}{$\alpha$} \\
\hline & Coef & Std Err & Coef & Std Err & Coef & Std Err \\
\hline Constant & $-7.34 * *$ & 0.05 & -11.40 & 17.94 & $-0.21 * *$ & 0.03 \\
\hline Driver 1 age & $-0.07 * *$ & 0.02 & -0.55 & 1.00 & $-0.09 * *$ & 0.01 \\
\hline Driver 1 age squared & $0.18^{* *}$ & 0.02 & -0.20 & 1.01 & $0.06^{* *}$ & 0.01 \\
\hline Driver 1 female & $0.09 * *$ & 0.02 & 0.00 & 1.02 & 0.00 & 0.01 \\
\hline Driver 1 single & $0.05^{* *}$ & 0.02 & 0.25 & 1.00 & $0.03^{* *}$ & 0.01 \\
\hline Driver 1 married & 0.07 & 0.04 & -0.68 & 1.00 & 0.04 & 0.02 \\
\hline Driver 1 credit score & -0.04 & 0.03 & 0.17 & 1.01 & $-0.09 * *$ & 0.01 \\
\hline Driver 2 indicator & $-0.35 * *$ & 0.07 & 0.61 & 1.00 & $-0.10 * *$ & 0.04 \\
\hline \multirow[t]{2}{*}{ Home value } & $-0.06 * *$ & 0.00 & -0.04 & 1.00 & $0.21 * *$ & 0.01 \\
\hline & & & Coef & Std Err & & \\
\hline$\sigma$ & \multicolumn{4}{|c|}{$\begin{array}{ll}6.57^{* *} & 0.24 \\
\end{array}$} & & \\
\hline Parameter mean & \multicolumn{2}{|c|}{0.0007058} & \multicolumn{2}{|c|}{0.0000} & \multicolumn{2}{|c|}{0.884} \\
\hline Parameter median & 0.0006 & 69 & 0.0 & & \multicolumn{2}{|c|}{0.794} \\
\hline
\end{tabular}

Note: Each variable $z$ is normalized as $(z-\operatorname{mean}(z)) / \operatorname{stdev}(z)$.

** Significant at 5 percent level.

Table A.17: Model 2 - At Most One Claim Core Sample (4170 Households)

\begin{tabular}{|c|c|c|c|c|c|c|}
\hline & \multicolumn{2}{|c|}{$r$} & \multicolumn{2}{|c|}{$\Lambda$} & \multicolumn{2}{|c|}{$\alpha$} \\
\hline & Coef & Std Err & Coef & Std Err & Coef & Std Err \\
\hline Constant & $-13.80 * *$ & 2.30 & $-19.72 * *$ & 2.49 & $-0.47^{* *}$ & 0.01 \\
\hline Driver 1 age & $-4.62 * *$ & 1.25 & -0.56 & 1.66 & $-0.06 * *$ & 0.01 \\
\hline Driver 1 age squared & $-1.00 * *$ & 0.49 & $-7.03 *$ & 3.73 & 0.00 & 0.01 \\
\hline Driver 1 female & 0.24 & 0.20 & -1.41 & 2.14 & $-0.02 * *$ & 0.01 \\
\hline Driver 1 single & -0.02 & 0.18 & -0.02 & 1.03 & 0.00 & 0.01 \\
\hline Driver 1 married & -1.54 & 2.21 & $4.12^{* *}$ & 1.54 & -0.01 & 0.01 \\
\hline Driver 1 credit score & 0.39 & 0.24 & -0.86 & 1.12 & $-0.05^{* *}$ & 0.01 \\
\hline \multirow[t]{2}{*}{ Driver 2 indicator } & -6.12 & 6.10 & -3.13 & 2.74 & 0.02 & 0.02 \\
\hline & & & Coef & Std Err & & \\
\hline$\sigma$ & & & $3.16^{* *}$ & 0.05 & & \\
\hline Parameter mean & \multicolumn{2}{|c|}{0.0000461} & \multicolumn{2}{|c|}{0.0000} & \multicolumn{2}{|c|}{0.637} \\
\hline Parameter median & \multicolumn{2}{|c|}{0.0000000} & \multicolumn{2}{|c|}{0.0000} & \multicolumn{2}{|c|}{0.633} \\
\hline
\end{tabular}

Note: Each variable $z$ is normalized as $(z-\operatorname{mean}(z)) / \operatorname{stdev}(z)$.

** Significant at 5 percent level.

* Significant at 10 percent level. 
Table A.18: Model 5 - At Most One Claim

Core Sample (4170 Households)

\begin{tabular}{|c|c|c|c|c|c|c|}
\hline & \multicolumn{2}{|c|}{$\mathbf{r}$} & \multicolumn{2}{|c|}{$\Lambda$} & \multicolumn{2}{|c|}{$\alpha$} \\
\hline & Coef & Std Err & Coef & Std Err & Coef & Std Err \\
\hline Constant & -3.87 & 3.60 & $-27.16^{* *}$ & 2.80 & $-0.48^{* *}$ & 0.01 \\
\hline Driver 1 age & $-7.29 *$ & 4.42 & $-11.04^{* *}$ & 1.88 & $-0.06 * *$ & 0.01 \\
\hline Driver 1 age squared & -1.44 & 1.38 & $-6.41 * *$ & 1.96 & $0.01 * *$ & 0.01 \\
\hline Driver 1 female & $-0.37^{* *}$ & 0.18 & $9.11^{* *}$ & 1.19 & $-0.02 * *$ & 0.01 \\
\hline Driver 1 single & -0.19 & 0.24 & $6.32 * *$ & 2.11 & 0.00 & 0.01 \\
\hline Driver 1 married & -0.45 & 0.37 & $11.60 * *$ & 2.13 & 0.00 & 0.01 \\
\hline Driver 1 credit score & 0.10 & 0.18 & $1.94^{* *}$ & 0.88 & $-0.05^{* *}$ & 0.01 \\
\hline Driver 2 indicator & 0.30 & 0.56 & $-12.63 * *$ & 1.71 & $0.02 * *$ & 0.02 \\
\hline \multirow[t]{2}{*}{ Home value } & 0.02 & 0.14 & $2.43^{* *}$ & 0.41 & 0.01 & 0.00 \\
\hline & & & Coef & Std Err & & \\
\hline$\sigma$ & & & $3.15^{* *}$ & 0.06 & & \\
\hline Parameter mean & \multicolumn{2}{|c|}{0.0000644} & \multicolumn{2}{|c|}{0.0014} & \multicolumn{2}{|c|}{0.637} \\
\hline Parameter median & \multicolumn{2}{|c|}{0.0000002} & \multicolumn{2}{|c|}{0.0000} & \multicolumn{2}{|c|}{0.630} \\
\hline
\end{tabular}

Note: Each variable $z$ is normalized as $(z-\operatorname{mean}(z)) / \operatorname{stdev}(z)$.

** Significant at 5 percent level.

* Significant at 10 percent level.

Table A.19: Model 2 Without Extreme Deductibles Core Sample (4170 Households)

\begin{tabular}{|c|c|c|c|c|c|c|}
\hline & \multicolumn{2}{|c|}{$\mathbf{r}$} & \multicolumn{2}{|c|}{$\Lambda$} & \multicolumn{2}{|c|}{$\alpha$} \\
\hline & Coef & Std Err & Coef & Std Err & Coef & Std Err \\
\hline Constant & $-11.85 * *$ & 1.47 & -21.49 & 14.72 & $-0.45 * *$ & 0.01 \\
\hline Driver 1 age & $-3.59 *$ & 1.85 & 0.53 & 8.25 & $-0.09 * *$ & 0.01 \\
\hline Driver 1 age squared & -0.57 & 0.60 & -15.34 & 12.03 & $0.02 * *$ & 0.01 \\
\hline Driver 1 female & -0.08 & 0.13 & 1.67 & 9.88 & $-0.01 *$ & 0.01 \\
\hline Driver 1 single & 0.24 & 0.22 & 1.95 & 14.84 & 0.01 & 0.01 \\
\hline Driver 1 married & -0.14 & 0.30 & -0.94 & 24.75 & -0.01 & 0.01 \\
\hline Driver 1 credit score & 0.02 & 0.13 & 1.58 & 2.77 & $-0.06 * *$ & 0.01 \\
\hline \multirow[t]{2}{*}{ Driver 2 indicator } & 0.21 & 0.46 & 10.42 & 12.90 & 0.02 & 0.02 \\
\hline & & & Coef & Std Err & & \\
\hline$\sigma$ & & & $2.46^{* *}$ & 0.07 & & \\
\hline Parameter mean & \multicolumn{2}{|c|}{0.0001114} & \multicolumn{2}{|c|}{0.0001} & \multicolumn{2}{|c|}{0.668} \\
\hline Parameter median & \multicolumn{2}{|c|}{0.0000094} & \multicolumn{2}{|c|}{0.0000} & \multicolumn{2}{|c|}{0.653} \\
\hline
\end{tabular}

Note: Each variable $z$ is normalized as $(z-\operatorname{mean}(z)) / \operatorname{stdev}(z)$.

** Significant at 5 percent level.

* Significant at 10 percent level. 
Table A.20: Model 2 - Auto Collision Only Core Sample (4170 Households)

\begin{tabular}{|c|c|c|c|c|c|c|}
\hline & \multicolumn{2}{|c|}{$r$} & \multicolumn{2}{|c|}{$\Lambda$} & \multicolumn{2}{|c|}{$\alpha$} \\
\hline & Coef & Std Err & Coef & Std Err & Coef & Std Err \\
\hline Constant & $-6.82 * *$ & 0.14 & -11.72 & 39.66 & $-0.20 * *$ & 0.02 \\
\hline Driver 1 age & $-0.43 * *$ & 0.08 & 1.83 & 2.89 & -0.01 & 0.01 \\
\hline Driver 1 age squared & 0.01 & 0.06 & $-5.92 * *$ & 2.73 & 0.01 & 0.01 \\
\hline Driver 1 female & $0.15^{* *}$ & 0.07 & 0.94 & 5.40 & $0.02 *$ & 0.01 \\
\hline Driver 1 single & -0.08 & 0.07 & -0.39 & 7.81 & -0.01 & 0.01 \\
\hline Driver 1 married & 0.10 & 0.09 & 1.48 & 1.84 & 0.00 & 0.01 \\
\hline Driver 1 credit score & $0.15 *$ & 0.08 & 0.93 & 8.39 & $-0.03^{* *}$ & 0.01 \\
\hline \multirow[t]{2}{*}{ Driver 2 indicator } & 0.16 & 0.17 & -1.73 & 3.33 & $0.10^{* *}$ & 0.02 \\
\hline & & & Coef & Std Err & & \\
\hline$\sigma$ & & & $3.26^{* *}$ & 0.12 & & \\
\hline Parameter mean & \multicolumn{2}{|c|}{0.0012839} & \multicolumn{2}{|c|}{0.0000} & \multicolumn{2}{|c|}{0.869} \\
\hline Parameter median & \multicolumn{2}{|c|}{0.0011647} & \multicolumn{2}{|c|}{0.0000} & \multicolumn{2}{|c|}{0.867} \\
\hline
\end{tabular}

Note: Each variable $z$ is normalized as $(z-\operatorname{mean}(z)) / \operatorname{stdev}(z)$.

** Significant at 5 percent level.

* Significant at 10 percent level.

Table A.21: Model 2 - Auto Comprehensive Only Core Sample (4170 Households)

\begin{tabular}{|c|c|c|c|c|c|c|}
\hline & \multicolumn{2}{|c|}{$\mathbf{r}$} & \multicolumn{2}{|c|}{$\Lambda$} & \multicolumn{2}{|c|}{$\alpha$} \\
\hline & Coef & Std Err & Coef & Std Err & Coef & Std Err \\
\hline Constant & $-6.70 * *$ & 0.20 & $-10.39 * *$ & 2.82 & $-0.37^{* *}$ & 0.02 \\
\hline Driver 1 age & $-0.21 * *$ & 0.08 & 1.44 & 2.54 & $-0.09 * *$ & 0.01 \\
\hline Driver 1 age squared & $0.18 * *$ & 0.06 & -2.17 & 12.66 & -0.01 & 0.01 \\
\hline Driver 1 female & 0.28 & 0.07 & 0.11 & 2.16 & $0.02 * *$ & 0.01 \\
\hline Driver 1 single & 0.02 & 0.09 & 1.16 & 3.52 & $-0.02 *$ & 0.01 \\
\hline Driver 1 married & $-0.09 * *$ & 0.14 & 0.02 & 1.12 & -0.02 & 0.02 \\
\hline Driver 1 credit score & -0.01 & 0.09 & 0.07 & 12.33 & $-0.03^{* *}$ & 0.01 \\
\hline \multirow[t]{2}{*}{ Driver 2 indicator } & 0.06 & 0.26 & -0.93 & 1.18 & 0.03 & 0.03 \\
\hline & & & Coef & Std Err & & \\
\hline$\sigma$ & & & $4.23 * *$ & 0.20 & & \\
\hline Parameter mean & \multicolumn{2}{|c|}{0.0016726} & \multicolumn{2}{|c|}{0.0000} & \multicolumn{2}{|c|}{0.692} \\
\hline Parameter median & \multicolumn{2}{|c|}{0.0014480} & \multicolumn{2}{|c|}{0.0000} & \multicolumn{2}{|c|}{0.696} \\
\hline
\end{tabular}

Note: Each variable $z$ is normalized as $(z-\operatorname{mean}(z)) / \operatorname{stdev}(z)$.

** Significant at 5 percent level.

* Significant at 10 percent level. 
Table A.22: Model 2 - Home All Perils Only Core Sample (4170 Households)

\begin{tabular}{|c|c|c|c|c|c|c|}
\hline & \multicolumn{2}{|c|}{$r$} & \multicolumn{2}{|c|}{$\Lambda$} & \multicolumn{2}{|c|}{$\alpha$} \\
\hline & Coef & Std Err & Coef & Std Err & Coef & Std Err \\
\hline Constant & $-11.29 * *$ & 0.53 & $-22.00 * *$ & 5.92 & $-0.40 * *$ & 0.02 \\
\hline Driver 1 age & $-0.51 * *$ & 0.18 & $14.98 * *$ & 5.79 & $-0.07 * *$ & 0.01 \\
\hline Driver 1 age squared & $0.96^{* *}$ & 0.17 & $-6.08 * *$ & 2.82 & $0.02 * *$ & 0.01 \\
\hline Driver 1 female & 0.26 & 0.19 & 4.08 & 2.86 & $-0.02 * *$ & 0.01 \\
\hline Driver 1 single & -0.05 & 0.20 & -2.22 & 1.70 & 0.01 & 0.01 \\
\hline Driver 1 married & -0.49 & 0.39 & $1.41^{* *}$ & 0.70 & 0.00 & 0.02 \\
\hline Driver 1 credit score & 0.17 & 0.23 & $-5.67 * *$ & 1.65 & $-0.08 * *$ & 0.01 \\
\hline \multirow[t]{2}{*}{ Driver 2 indicator } & -10.29 & 26.66 & -6.15 & 4.72 & -0.02 & 0.03 \\
\hline & & & Coef & Std Err & & \\
\hline$\sigma$ & & & $1.83^{* *}$ & 0.05 & & \\
\hline Parameter mean & \multicolumn{2}{|c|}{0.0000749} & \multicolumn{2}{|c|}{0.0064} & \multicolumn{2}{|c|}{0.684} \\
\hline Parameter median & \multicolumn{2}{|c|}{0.0000174} & \multicolumn{2}{|c|}{0.0000} & \multicolumn{2}{|c|}{0.668} \\
\hline
\end{tabular}

Note: Each variable $z$ is normalized as $(z-\operatorname{mean}(z)) / \operatorname{stdev}(z)$.

** Significant at 5 percent level.

Table A.23: Model 2 with Coverage-Specific Choice Noise Core Sample (4170 Households)

\begin{tabular}{|c|c|c|c|c|c|c|}
\hline & \multicolumn{2}{|c|}{$\mathbf{r}$} & \multicolumn{2}{|c|}{$\Lambda$} & \multicolumn{2}{|c|}{$\alpha$} \\
\hline & Coef & Std Err & Coef & Std Err & Coef & Std Err \\
\hline Constant & $-9.21 * *$ & 0.26 & -18.51 & 29.42 & $-0.40 * *$ & 0.01 \\
\hline Driver 1 age & $-0.72 * *$ & 0.15 & 0.01 & 0.99 & $-0.04^{* *}$ & 0.01 \\
\hline Driver 1 age squared & $0.19 *$ & 0.11 & -6.22 & 21.34 & 0.00 & 0.00 \\
\hline Driver 1 female & $0.23 * *$ & 0.11 & -0.06 & 1.01 & 0.00 & 0.01 \\
\hline Driver 1 single & -0.02 & 0.11 & 0.53 & 2.21 & 0.00 & 0.01 \\
\hline Driver 1 married & -0.24 & 0.22 & 1.33 & 4.99 & -0.01 & 0.01 \\
\hline Driver 1 credit score & $0.37^{* *}$ & 0.10 & 1.18 & 4.26 & $-0.04^{* *}$ & 0.00 \\
\hline Driver 2 indicator & -9.01 & 11.93 & -3.53 & 12.45 & 0.00 & 0.02 \\
\hline$\sigma$ & $1.64^{* *}$ & 0.05 & $3.98^{* *}$ & 0.11 & $4.79^{* *}$ & 0.16 \\
\hline Parameter mean & \multicolumn{2}{|c|}{0.0001132} & \multicolumn{2}{|c|}{0.0000} & \multicolumn{2}{|c|}{0.678} \\
\hline Parameter median & \multicolumn{2}{|c|}{0.0000699} & \multicolumn{2}{|c|}{0.0000} & \multicolumn{2}{|c|}{0.676} \\
\hline
\end{tabular}

Note: Each variable $z$ is normalized as $(z-\operatorname{mean}(z)) / \operatorname{stdev}(z)$.

** Significant at 5 percent level.

* Significant at 10 percent level. 